\title{
(Glycosylphosphatidylinositol-Based) Protein Chips and Biosensors for Biopharmaceutical Process Analytics
}

\section{Günter Müller*}

Department I, Genetics, Biocenter, Ludwig-Maximilians-University Munich, 82152 Martinsried near Munich, Germany

\begin{abstract}
Prior to the introduction of regulated process validation activities it was generally assumed that the production process for protein drugs per se is under control and appropriate for their generation, if the final product fulfils the criteria raised for the bioanalytical quality end control for therapeuticals. However nowadays, the production process is being considered in a much deeper and considerably more differentiated fashion. The use of in-process and on-/at-line controls and supervisions on a regular basis encompassing all critical parameters about the individual sub-processes and the emerging intermediary and side products is generally thought to significantly contribute to the demonstration that the production process is under control at the time point of the measurements and with high probability also thereafter. The deep understanding of the interrelationship between process and product can not completely eliminate but will considerably reduce the risk for the emergence of product variants, impurities and contaminants during critical sub-processes that may escape detection during final quality control for technical and/or economical reasons. The test systems required for elucidation of the multiple process-product interactions have to be chosen, validated and calibrated according to commonly accepted and approved criteria. In the near future novel platform technologies, such as protein chips and biosensors that are based on novel capturing/immobilising probes, e.g. glycosylphosphatidylinositol-anchored proteins, and detection probes, e.g. nanoparticles, will greatly contribute to the rapid and reliable measurement of many samples for multiple parameters in cell-free and cell-based assay configurations in parallel rather than consecutive fashion.
\end{abstract}

Keywords: Assay validation; Bioanalytical assays; Biosensors; Glycosylphosphatidylinositol; Nanoparticles; Protein chips; Protein drug production; Proteomics; Qualification and calibration; Quality control

Abbreviations: GPI: Glycosylphosphatidylinositol; GPI-proteins: GPI-anchored proteins; HCPs: Host cell proteins; NPs: Nanoparticles

\section{Introduction}

The scope of each process validation for the biopharmaceutical production of protein drugs is the demonstration that the manufacturing procedures envisaged will lead with high reproducibility and accuracy to a therapeutical that meets all patient's requirements with regard to safety and efficacy. Prior to the introduction of regulated process validation activities it was generally assumed that the production process per se is under control and appropriate for the generation of the protein therapeutical, if the final product fulfils the criteria requested for the bioanalytical quality end control. Accordingly, successful quality end control would be sufficient for approval of a protein therapeutical for the relevant purpose, e.g. phase I clinical studies. However nowadays, the production process is being considered in a much deeper and considerably more differentiated fashion, including its reproducibility and robustness during upstream and downstream processing in the industrial large-scale and under routine conditions as well as the possibility of the generation of undesired modifications of the protein therapeutical and of unexpected rare contaminations and impurities which might fail to be detected during routine quality end control. The use of in-process controls and supervisions on a regular basis encompassing all critical parameters about the individual sub-processes and the emerging intermediary and side products is generally thought to contribute to the demonstration that the process is under control at the time point of the measurements and with high probability also thereafter. Consequently, the development of production processes for protein drugs necessitates the rapid introduction of process analytics for both upstream and downstream processes [1-3].
Protein drugs must not only fulfil high-level product quality and safety requirements as requested by the regulatory agencies. In addition, they have to be introduced in the market in short time. As a consequence, at present the strategies for process development of protein drug purification are based on the scaling-up of procedures already implemented for the scale of laboratory or bench use and usually rely on the know-how of scientists and engineers upon successful experimentation at the lab and preclinical level. Nevertheless or for that reason this strategy often leads to sub-optimal individual steps regarding the technical equipment and auxiliary materials. Consequently, strategies and tools are urgently required that will generate optimal long-term solutions on the basis of a rational design in developing each step of the production process $[4,5]$.

One strategy to approach this goal comprises the willingness to add to the currently used process development paradigm intensive efforts for the introduction of novel and attractive analytical tools, which will enable a more systematic and rationale design of the optimization strategy for the production of protein drugs. Examples for those tools encompass the so-called "high-throughput experimentation" (HTE) methods [6-8] and computer-aided process designing tools [9-11]. It is also of considerable importance to implement those novel designing tools during the development quite early since alterations in the

*Corresponding author: Günter Müller, Sanofi Germany GmbH, R \& D Diabetes, Industrial Park Höchst, Bldg. H821, 65926 Frankfurt am Main, Germany, Tel: +4969 305 4271; Fax: +4969 305 81901; E-mail: guenter.mueller@sanofi.com

Received December 14, 2011; Accepted February 10, 2012; Published February 13,2012

Citation: Müller G (2012) (Glycosylphosphatidylinositol-Based) Protein Chips and Biosensors for Biopharmaceutical Process Analytics. J Bioprocess Biotechniq 2:115 doi: 10.4172/2155-9821.1000115

Copyright: (c) 2012 Müller G. This is an open-access article distributed under the terms of the Creative Commons Attribution License, which permits unrestricted use, distribution, and reproduction in any medium, provided the original author and source are credited. 
production process and its analytical control may elicit considerable technological and regulatory risks [12]. The use of innovative designing and analytical tools for process monitoring and control is nowadays strongly encouraged by the US Food and Drug Administration (FDA) as delineated by its Process Analysis Technology (PAT) [13] and Quality by Design (QbD) [14] initiatives. The general mindset underlying these initiatives relies on the assumption that a deep understanding of the critical and rate-limiting process parameters will have the strongest positive influence on the quality of the protein drug produced.

In the early days of the biotechnological generation of protein drugs a thorough understanding of the production process was missing in most cases and the impact of the individual process parameters on the quality of the protein product could not be predicted in a reliable and adequate fashion. The ongoing improvement of bioanalytics and the underlying technologies as well as of the data evaluation caused an important shift in the analytical paradigm. On-/at-line sensors and measurement techniques allow the continuous determination of those process parameters critical for the adequate control of upstream and downstream processing. The introduction of statistical methods for data evaluation, like principal component analysis (PCA), facilitates the elucidation of the relationship between the process variables and the critical and rate-limiting process parameters. The availability of real-time data usually will have tremendous impact on the proper understanding of the production process. Thus the pro-active application of analytical data will create important novel opportunities within the production environment. A representative list of the molecular criteria for the quality assessment of the protein drug to be determined along its production and the analytical tools commonly used is given in Table 1 .

\section{Criteria for Process Analytical Methods Used for Protein Drug Production}

The development of recombinant proteins as pharmaceutical drugs requires robust, sensitive and specific analytical assays to characterize the purified product with respect to its physicochemical as well as biological features, as well as bioactivity assays to quantify its protein amount and functionality in biological matrices. Wellestablished analytical assays are applied to determine the purity, absence of impurities and contaminants, identity, quantity, stability, specificity and potency of the purified recombinant protein during process development. The determination of the purity and identity of a protein drug is a particularly challenging task since recombinant proteins are produced from living systems that inherently lead to protein variants (e.g. post-translationally modified and/or fragmented

\begin{tabular}{|c|c|c|c|}
\hline Protein Characteristic & Analysis Properties & (GPI-) Protein Chip & Alternative Methods \\
\hline \multirow[t]{3}{*}{ Physical and Chemical } & identity & Yes & $\begin{array}{l}\text { isoelectric focusing } \\
\text { peptide mapping } \\
\text { ion exchange HPLC }\end{array}$ \\
\hline & purity & No & $\begin{array}{l}\text { electrophoresis } \\
\text { reverse phase HPLC } \\
\text { size exclusion HPLC }\end{array}$ \\
\hline & $\begin{array}{l}\text { integrity/ } \\
\text { molecular weight }\end{array}$ & yes/no & $\begin{array}{l}\text { SDS electrophoresis } \\
\text { mass spectrometry } \\
\text { size exclusion HPLC } \\
\text { light scatter }\end{array}$ \\
\hline \multirow{2}{*}{$\begin{array}{l}\text { Potency and } \\
\text { Activity }\end{array}$} & antigen binding & Yes & ELISA \\
\hline & cell-based assays & Yes & $\begin{array}{l}\text { cell proliferation } \\
\text { cellular signaling } \\
\text { cell metabolism } \\
\text { cytotoxicity } \\
\text { reporter-gene assays }\end{array}$ \\
\hline Product-related Impurities & $\begin{array}{l}\text { aggregation } \\
\text { fragmentation } \\
\text { conformation } \\
\text { (secondary, tertiary structure) }\end{array}$ & (yes) & $\begin{array}{l}\text { native electrophoresis } \\
\text { Fourier-transformed infra-red (FTIR) } \\
\text { size exclusion HPLC } \\
\text { circular dichroism } \\
\text { micro-rheometry } \\
\text { differential scanning calorimetry } \\
\text { raman spectroscopy } \\
\text { dynamic/static light scatter } \\
\text { analytical ultracentrifugation } \\
\text { ultrasound }\end{array}$ \\
\hline \multirow[t]{7}{*}{ Process-related Contaminants } & host cell protein & Yes & ELISA \\
\hline & host cell DNA & No & $\begin{array}{l}\text { DNA hybridisation } \\
\text { qPCR } \\
\text { DNA binding-threshold } \\
\text { Fluorescent-picogreen }\end{array}$ \\
\hline & protein A & Yes & ELISA \\
\hline & medium proteins & Yes & ELISA \\
\hline & viruses & Yes & $\begin{array}{l}\text { qPCR } \\
\text { electron microscopy } \\
\text { in vivo/vitro assays }\end{array}$ \\
\hline & microorganisms & Yes & $\begin{array}{l}\text { "Bioburden" } \\
\text { endotoxin-LAL test }\end{array}$ \\
\hline & $\begin{array}{l}\text { column/vessel leachates/extractables } \\
\text { cell culture components } \\
\text { reagents } \\
\text { chemicals }\end{array}$ & (yes) & $\begin{array}{l}\text { various } \\
\text { e.g. reverse phase HPLC } \\
\text { ion chromatography } \\
\text { GC-MS }\end{array}$ \\
\hline
\end{tabular}

Table 1: Test methods for process analytics of protein drug production. 
proteins) with altered characteristics, which may be difficult to separate from the authentic protein drug. In stability studies, those structural/ functional features are evaluated that might be subject to change during storage/handling of the drug. Specificity measurements lead to a closer understanding of drug-target interaction(s), which might result in early hints about possible side effects in clinical trials. Finally, potency determinations are used to quantify the biological activity of the therapeutic protein.

On the other hand, bioanalytical assays are necessary to determine and quantify the protein drug in biological fluids. For example, validated bioanalytical assays are the key in the quantification of the protein drug in the course of pharmacokinetic studies. In particular, in the case of humanized/human monoclonal antibodies, bioanalytical assay development in human serum/plasma is challenging since the therapeutic concentration of antibodies can be very low ( 0.1 to 10 $\mu \mathrm{g} / \mathrm{ml}$ or even lower), and because these antibodies are so similar to the native human antibodies that circulate in the blood at very high concentrations (up to $10 \mathrm{mg} / \mathrm{ml}$ ).

Another major topic of scientific and regulatory consideration in the development of therapeutic proteins is the assessment of undesired immune responses toward the drug that may lead to a reduction in its efficacy and to adverse reactions. This assessment also requires validated bioanalytical assays, which allow to precisely measure the immune response. In future, there will be an even greater emphasis on the (bio) analytical description of biological substances because of an increase in numbers of protein therapeutics in clinical development, and of the advent of generics of biological drugs of the 1st generation (e.g. insulin and its variants) and the task of evaluating these compounds for clinical use. Developing methods and protocols for assessing bioequivalence of an original drug and its generics is a high priority for the FDA according to the current FDA Commissioner [15].

Taken together, the continuous measurement and control of all critical process parameters along the complete production process, which constitutes part of the so-called PAT initiative of the FDA, will significantly reduce the risk for the emergence of unexpected and non-predictable product variants as well as of contaminants not related to the product. Consequently, the deep understanding of the interrelationship between process and product can not eliminate but will considerably reduce the risk for the emergence of product variants and contaminants during critical sub-processes that escape detection during routine quality end control for technical or economical reasons.

\section{Methods Currently Available for the Process Analytics of Protein Drug Production}

During the last two decades a number of innovative analytical tools and methods has been introduced for the assessment of the quality and efficacy of the process for the recombinant production of protein drugs. They include chemometric sensors of high sensitivity and reliability [16] as well as on-line or at-line determinations of metabolites,

\begin{tabular}{|l|l|l|l|l|}
\hline Format & $\begin{array}{l}\text { Direct Quan- } \\
\text { tification }\end{array}$ & $\begin{array}{l}\text { Identifi- } \\
\text { cation }\end{array}$ & $\begin{array}{l}\text { Limit of } \\
\text { Detection }\end{array}$ & Use \\
\hline ELISA & yes & no & $1-100$ & $\begin{array}{l}\text { lot release testing } \\
\text { process control }\end{array}$ \\
\hline $\begin{array}{l}\text { Western Blot- } \\
\text { ting }\end{array}$ & semi & yes & $20-200$ & process characterisation \\
\hline $\begin{array}{l}\text { (GPI-) Protein } \\
\text { Chip }\end{array}$ & yes & yes & $0.1-200$ & $\begin{array}{l}\text { process control and } \\
\text { characterisation }\end{array}$ \\
\hline
\end{tabular}

Table 2: Comparison of the (GPI-) protein chip, ELISA and Western blotting formats for assaying HCP during process analytics of protein drug production. nutrients, product and degradation products $[17,18]$. The use of those technologies will certainly narrow the gap usually existing between the understanding and the control of upstream processing. Protein chips and microarrays will become standard tools for the high-throughput analysis of protein expression. Chip technologies will also facilitate the fast characterization of the recombinant protein drug, even in brothes derived from process intermediates. Protein chips have already been successfully used for the purification and quantification of monoclonal antibodies and degradation products, such as half-antibodies, by capillary gel electrophoresis $[19,20]$. Chips specific for glycan structures have already been applied as tool to monitor glycosylated protein drugs. Moreover, the combination with sophisticated bioinformatical methods and relevant software tools will increasingly contribute to efficient clone screening and selection as well as to rational process development. A comparison of the major classes of the currently used methods for the identification of contaminations and impurities in protein drug preparations with host cell protein (HCP) during process development is given in Table 2.

\section{Errors and Heterogeneity in the Production of Protein Drugs}

Protein drugs, such as peptide hormones, growth factors, blood coagulation factors, enzymes and antibodies, are produced at large scale by recombinant microorganisms, such as bacteria (e.g. E. coli), funghi (e.g. yeast) or cultured mammalian cells (e.g. COS), predominantly, rather than by old-fashioned extraction from animal tissues or isolation from human plasma. Probably the best-known example represents the blood glucose-lowering polypeptide hormone, insulin, that is not available at adequate amounts in diabetic patients and therefore has to be substituted for by exogenous administration. Microorganisms become forced to synthesize the protein drug upon having received the corresponding information, i.e. the cDNA gene encoded by a circular

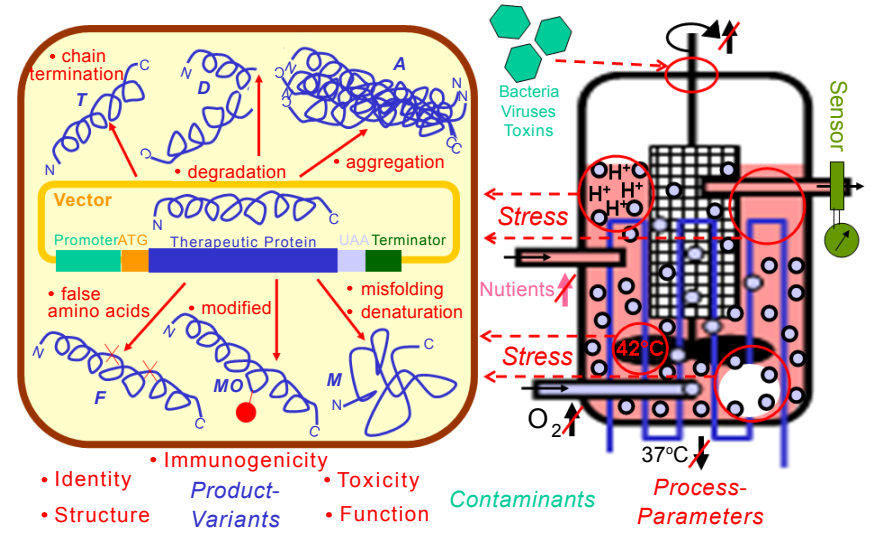

Figure 1: Errors and heterogeneity in the biotechnological production of protein drugs. Ectopic expression of protein drugs in recombinant host cells, such as bacterial, yeast and mammalian cells may lead to multiple product variants ( $T, D$, $A, F, M O, M)$ due to the operation of multiple physiological and stress response pathways under normal and sub-optimal growth conditions, respectively. Critical parameters for the quality of the resulting product variants may be differentially affected and become further impaired during fermentation in the large scale. The accompanying sub-optimal process parameters will lead to cellular stress due to local nutrient and oxygen depletion or $\mathrm{pH}$ and temperature increase. These deviations from the optimal process will not be recognized by sensors operating outside of the bioreactor. Furthermore, bioreactors are susceptible for infiltration by contaminants. $A$, aggregated protein; $D$, degraded protein; $F$, protein with false amino acids incorporated; $M$, misfolded denatured protein; $M O$, posttranslationally modified protein; $\mathrm{T}$, prematurely terminated protein. 
DNA vector together with the appropriate upstream and downstream regulatory elements for transcription and translation. In many cases the microorganisms will produce the desired protein drug in functional state and in sufficient amounts for subsequent preparation and purification.

Microorganisms like human beings make errors. Moreover, populations of microorganisms like their human counterparts become heterogeneous with time. In consequence, the number and types of errors in protein drugs will increase with the scale and duration of the fermentation process. Errors occurring during protein synthesis in microorganisms include (Figure 1) the (i) incorporation of false or unphysiological (e.g. norleucine) amino acids leading to mutant proteins, (ii) premature termination of polypeptide elongation leading to carboxy-terminally shortened proteins, (iii) incorrect folding into the three-dimensional conformation leading to misfolded proteins, (iv) intracellular aggregation leading to protein precipitates or fibrilles and (v) intracellular proteolytic degradation leading to protein fragments [21-25]. These errors may have severe implications for the resulting protein variant with regard to its (i) molecular identity as reflected in the amino acid sequence (and already caused by a single amino acid exchange), (ii) structure as reflected in the three-dimensional conformation, (iii) physiological function as reflected in hypo- or hyperactivity (and putatively already caused by a single amino acid exchange), (iv) immunogenic potential as reflected in adverse antigenic response (and putatively already caused by a single amino acid exchange) and (v) toxicological potential as reflected for instance in proliferative activity with accompanying risk for cancer or protein aggregation with accompanying risk for embolic complications (and putatively already caused by a single amino acid exchange). The rate of errors in protein synthesis of non-recombinant and recombinant microorganisms under physiological growth conditions is rather low. However, this may change considerably upon their fermentation in bioreactors at large industrial scale. Microorganisms are usually grown in continuously operating bioreactors that are permanently fuelled with fresh glucose-containing medium under accompanying removal of the consumed glucose-deprived medium as well as with oxygen under concomitant precise control of the $\mathrm{pH}$ (by addition of buffering agent) and temperature (by cooling) of the medium (Figure 1).

\section{The Origin of Contaminants and Impurities Generated during Recombinant Production}

The 1994 draft, "Points to Consider in the Manufacturing and Testing of Monoclonal Antibody Products for Human Use" issued by the FDA [26] suggests that "wherever possible, contaminants should be below detectable levels using a sensitive assay capable of detecting $1 \mathrm{ppm}$ expressed on a weight basis with respect to the monoclonal antibody". In practise, this often requires immunological assays, such as ELISAs, developed specifically to quantify known contaminants. This approach is likely to be required to measure the amounts of any cell culture medium additives, e.g. bovine serum albumin, transferrin, methotrexate, or any process-related contaminants, such as protein $\mathrm{A}$ or $\mathrm{G}$ molecules, leached from chromatography columns. In addition, HCPs also need to be measured. The development of such assays is not a trivial task as potentially a very wide range of molecules could contaminate the purified product [27]. Fortunately, with highly productive cell lines grown in serum-free or protein-free media, the purity target is usually not too difficult to achieve. This is particularly true when affinity chromatography is used in conjunction with one or more ion exchange separations.

The DNA specification is tighter than that of other contaminants with a recommended limit of no more than 100 pg cellular DNA per dose [26]. Often a target specification is set in the early stages of a product development program before the dose has been finalized and in these cases a specification is set that is based on the weight of the product, e.g. 1-10 pg DNA per mg antibody. It is not unusual for the specification to be set at the limit of quantification of the assay, as it is technically quite challenging to measure pg or sub-pg quantities of DNA in a concentrated protein solution. The level of DNA clearance required can be equivalent to 10 logs of deprivement or more.

Many mammalian cell lines are known to harbour viruses. In the past a number of biopharmaceutical products were used for therapy that have been contaminated by viruses and subsequently infected patients [28]. Therefore, viruses present a particular issue for the production of protein drugs when mammalian cell lines are used [29]. In addition to a thorough characterization of the cell line used for protein production and the testing of in-process samples, there are guidelines issued by the US and European regulatory authorities [26,30] relating to the incorporation of virus removal or inactivation steps in the purification process. In general, it is recommended that the purification schemes include at least one "robust" virus removal or inactivation step, such as solvent-/detergent- or low $\mathrm{pH}$-treatment, or filtration steps. In addition, the chromatographic procedures used should also remove or inactivate viruses. The overall level of virus removal or clearance required is set by the number of virus-like particles detected in the unpurified bulk supernatant, which can be of the order of $10 \mathrm{E} 8$ or $10 \mathrm{E} 9$ per $\mathrm{ml}$ [31] A safety margin of 3-6 logs is suggested [26], but it has been proposed that the safety margin should be variable and be dependent on the consequences of accidental exposure to the virus and the likelihood that a single virus particle will be pathogenic [28]. A similar strategy is based on the calculation of virus removal or clearance required on the probability that a single dose of product will contain a single virus particle. The figure that has been used for tissue plasminogen activator is a probability of less than 1 in 10E6 [32]. These types of calculations are often based on the assumption that a minimum of 15 logs of virus clearance/inactivation is required for the overall purification process.

In addition to the quantifiable targets in terms of the clearance of various contaminants, a key aspect of the purification of protein drugs is its "robustness" or tolerance to small variations in processing conditions. "Robustness" is directly related to the failure rate. With considerable time and money invested in the upstream production of a batch of protein drugs, the failure rate must be kept to an absolute minimum. It is essential to determine for each step of a purification procedure the key parameters that influence the performance of that step. For example ion echange chromatographical operations are sensitive to the $\mathrm{pH}$ and conductivity of the various equilibration, washing and elution buffers used. It is important to design those steps such that minor variations in the relevant parameters do not result in a decreased purification performance. As an additional precaution, some redundancy is frequently built into a purification process so that should one step perform poorly, subsequent steps can make up the deficiency and the final protein drug product will still meet the specifications. Thus the penultimate or the final step may be a polishing step that can remove process contaminants, but in most cases does not actually do so, as they have already been removed by preceding steps.

The absolute purity of a protein drug is often difficult, if at all possible, to determine. Regular and sometimes only subtle protein modifications, such as glycosylation, alternative disulfide bond formation, deamination, oxidation, phosphorylation, acetylation, sulfation, sulfoxidation, $\quad \gamma$-carboxylation and pyroglutamate 
formation, lead to protein variants that may have more or less different characteristics. Also, truncated protein variants might be generated by the presence of cryptic or alternative start sites of transcription, by premature stop of the peptide chain elongation process, or by the action of host cell peptidases. Peptide mapping and mass spectrometry usually guarantee the detection of the majority of such protein variants. Aggregation is another modification of protein drugs, which can be the result of, for example, underglycosylation, oxidation, and/or deamination, and can be detected by size-exclusion chromatography. The amount of aggregated protein usually should account for less than $5 \%$. It is highly recommended to investigate the nature and potential toxicity of such alterations. To analyse these variants is an essential yet challenging task, as their physicochemical features might not be very different from each other. Owing to the possible presence of highly related protein variants in the preparation, it is recommended to determine the purity of a protein drug by at least two independent methods, that is, methods that use different physicochemical principles, such as SDS-polyacrylamide gel electrophoresis and reverse-phase high pressure liquid chromatography.

Besides these protein variants, so-called process-related impurities have to be considered. Of major concern are residual antibiotics from fermentation, enzymes and antibodies from chromatography columns and other column leachates, endotoxin from bacterial hosts [33], (retro-) viruses [34], bacteria, fungi, mycoplasma, prions, various other media components, such as solvents, antifoam agents, heavy metal ions, as well as preservatives and HCPs. As for DNA contaminants, less than 10 to $100 \mathrm{pg}$ per dose are allowed in the final drug product [35]. To check for the presence of antigenic expression host-related impurities, a polyclonal antiserum to the "empty" host, that is HCPs derived from host cells which are not expressing the product-encoding gene, is very helpful. Moreover, whenever possible, specific impurity standards should be used for impurity quantification and the limit of detection/ quantification (LOD/LOQ) for impurity assays should be indicated. The acceptance limits should not be set higher than safety data justify, and it should not be lower than what is historically achievable by the production process and by reasonable analytical efforts. In some instances, the protein drug is conjugated to effector functions, such as radioisotopes, toxins, or other proteins, such as cytokines, that mediate the biological effect. Besides considering all aspects mentioned above for the individual components of the conjugate, special care has to be taken to determine the average coupling ratio as well as the amount of free components, if any, in the preparations.

\section{Detection of Host Cell Proteins}

Host cell proteins (HCPs) represent a complex set of analytes that have to be determined at very low concentrations (ppm or ng HCP per mg protein drug). The introduction of an adequate assay may be the most challenging task for process development. The assay system has to detect a wide array of analytes with high specificity and selectivity. Consequently, HCPs are commonly analysed with the use of immunoassay methods [27,36]. In most cases antibodies are raised against all the antigenic polypeptides expressed in the host cell line, which does not harbour the specific gene coding for the protein drug (so-called null cell line) $[37,38]$. Upon cultivation of the null cell line, the lysate proteins are extracted by procedures identical to those of the large-scale production process. Moreover, partially purified antigen preparations derived from selected steps of the large-scale purification process, may also be useful for generation of the antisera [39-41].

Three main formats of the immunoassays are currently in use, (i) conventional ELISA, (ii) Western blotting (involving electrophoretic separation of the HCPs and their electrotransfer onto a membrane, followed by decoration of the membrane with the anti-HCP antiserum) and (iii) protein chips (see below). Western blotting is rather effective for process characterization. It generates data about the efficacy of the individual purification steps for the elimination of particular HCPs. However, the technique of Western blotting is rather expensive and labour-intensive, that prevents it from application in automated and routine fashion, and therefore can not be used for online process control. Thus ELISA and protein chip technologies are the methods of choice for the overall quantitative evaluation of the levels of HCPs. The most challenging task for the development of both the ELISA and the protein chip formats is the accurate quantification of each individual HCP within a large concentration range by the same assay. For instance, as calibration standard the same mixed antigen preparation is commonly used that served for the preparation of the antisera for these assays. Upon immunization the range of HCPs in this preparation will trigger different immune responses and the generation of a variety of polyclonal antibodies with different affinities for each HCP. As a consequence, individual HCPs may yield different response factors in the ELISA and protein chip assays. This may impair the accuracy of both formats. Nevertheless, in practise the data obtained for samples derived from distinct process steps can be compared and will provide limits for appropriate process control. The principal procedures for the ELISA and protein chips represent standard immunoassay formats which can be automated and modified in straight-forward fashion to fit to at-/on-line process control where necessary. The relative merits of the three formats are given in Table 2.

For instance, protein A affinity chromatography represents a very efficient process step that is commonly used during purification for the production of monoclonal antibodies. It enables the highly efficient purification of the product in a single step. Importantly, any leaching of protein A from the column matrix will contaminate the therapeutic antibody and necessitate the unequivocal demonstration of removal of the protein A during the subsequent purification steps. Protein A is commonly detected by a conventional immunoassay. The method has to enable the dissociation of the protein $\mathrm{A}$ from the therapeutic antibody for accurate measurement, which in most cases is provoked by incubation at low $\mathrm{pH}(<4)$ or detergent. The aim for both the ELISA and the protein chip technologies should be to approach limits of detection of less than $1 \mathrm{ppm}$ (i.e. $1 \mathrm{ng}$ protein per $\mathrm{mg}$ therapeutic antibody) to guarantee acceptable elimination of protein A [39].

Various sources for protein A are available and used for the commercial purification of therapeutic antibodies in pharmaceutical industry. The distinct protein A entities have varying size distribution and are heterogeneous in their accessibility to and extent of proteolytic degradation. Consequently, each species will trigger different response factors during the antibody generation for the immune assay. Thus, a specific assay standard is needed for each protein A species with the aim of its accurate quantitative evaluation relative to the standard in case of leaching from the purification matrix. Similar to the HCP assay, the ELISA and protein chip technologies represent standard immunoassay formats which can be readily automated and adapted for integration into at-/on-line process control if required.

\section{Generation of Product Variants during Upstream Processing}

Homogeneous and stable conditions regarding the most critical growth and fermentation process parameters, such as glucose, $\mathrm{O}_{2}$, 
$\mathrm{pH}$, temperature, inside the bioreactor vessel are often thought to be adequately maintained by rigorous and continuous mixing using a motor-driven propeller or bubbling of air. However, during large-scale operation of bioreactors, heterogeneities in the fermentation process parameters at certain local areas in the bioreactor vessel can not be avoided per se due to a number of technical and practical reasons. This may lead to the genesis of "hidden" spaces of poorly bubbled oxygenand glucose-deprived and $\mathrm{H}^{+}$-enriched medium "clouds" as well as of areas of elevated temperature at the surface of the propeller wings due to limited exchange with the surrounding medium of the heat generated by the propeller rotation (Figure 1). These local deviations from the optimal and homogeneous growth milieu for the microorganisms can not be prevented by simply increasing the influx of fresh medium or oxygen, the speed of the propeller or efficacy of the cooling. This would cause negative osmotic or toxic effects by high local concentrations of glucose or oxygen radicals, lead to undesired foam formation, further increase the temperature at the propeller surface or decrease the temperature in the immediate vicinity of the cooling device. The emergence of those local heterogeneities and deviations from the optimal fermentation parameters is favoured by the difficulties or even inability in recognizing them during the running process. For reasons of maintenance of sterile conditions and technical realization, the sensors for glucose, oxygen, $\mathrm{pH}$ and temperature are usually installed outside rather than inside the fermenter vessel at the critical positions. In consequence, the critical fermentation parameters are routinely measured at the efflux channel for the consumed medium. However, this mode of measurement provides average values for those process parameters, only. Nevertheless, these values will be used for the control and regulation of the fermentation process on basis of the simplifying assumption that they reflect the real conditions prevalent inside the vessel. Thus, the operators are prevented from proper recognition and, in consequence, from appropriate correction/counterregulation of local deviations from the optimal fermentation conditions.

In contrast, microorganisms will experience any sub-optimal growth conditions and try to overcome them by the initiation of stressinduced salvage pathways (Figure 1). In fact, the excessive production of ectopic "foreign" proteins in microorganisms per se exerts cellular stress that will induce physiological stress responses, which involve complex gene expression programmes for promoting cell survival and down regulation of functions that are not vital or even harmful for the microorganism. These include the (i) incorporation of unphysiological or false amino acids into (passenger) proteins in case of lack of certain amino acids in order to maintain the synthesis of vital proteins, (ii) premature chain termination of (passenger) proteins in order to save energy and (iii) degradation or aggregation of (passenger) proteins in order to avoid toxic effects due to their accumulation. Thus, each of these responses represents part of a physiological anti-stress strategy of the microorganism faced with the excessive production of a protein drug at large scale. But each of these responses may be responsible for the generation of undesired protein product variants of varying structure in varying amount. Furthermore, the growth of microorganisms in an industrial bioreactor always implies the danger of putatively contaminating the content of the fermenter, including the protein product, with foreign agents, such as bacteria and viruses (Figure 1). This is best exemplified with the most critical site of bioreactors of the "propeller" type, the bearing of the propeller axle in the vessel wall. It is technically difficult to create complete tightness for very small particles, such as viruses.

\section{Product Variants and Contaminants during Downstream Processing}

The possibility of the emergence of product variants and contaminants is not limited to the fermentation of the microorganisms, i.e. the upstream processing, but also encompasses the downstream processing for the preparation and purification of the final protein drug (Figure 2). This includes (i) the separation of the microorganisms from the medium by filtration or centrifugation in a separator, (ii) the homogenization of the collected microorganisms, e.g. by high pressure in the so-called "French Press", (iii) the conversion of immature, inactive and unfolded precursor polypeptide, that is often synthesized as the primary gene product in the microorganism, into the mature, active and correctly folded protein drug by specific processing steps, (iv) the purification of the mature protein from accompanying medium components and HCPs, including preservatives, anti-foam reagents, buffer substances, ions, nutrients, nucleic acids and lipids, by typical column chromatography procedures and finally (v) the concentration of the mature and purified but diluted protein drug by precipitation with high salt. This general scheme for downstream processing can be varied in multiple fashion, including the expression of the protein drug as insoluble inclusion bodies in the cytoplasm of bacteria or as secreted soluble entities in the growth medium of cultured mammalian cells. Each step specific for these expression systems, such as the refolding of the polypeptide from inclusion bodies, may contribute to the emergence of additional product variants and contaminants.

Furthermore, none of these steps during downstream processing operates with $100 \%$ efficacy, as is the case for the apparently simple separation of the medium from the host cells as well as the complex conversion of the unfolded precursor product into the mature protein drug. In consequence, medium components and precursor product putatively contaminate the product along all stages during the production process. Moreover, along the complete production process the protein drug is in contact to numerous "foreign" agents, such as column materials (e.g. silica beads) for the purification, which may not be stable but susceptible to aging, as well as the reagents used

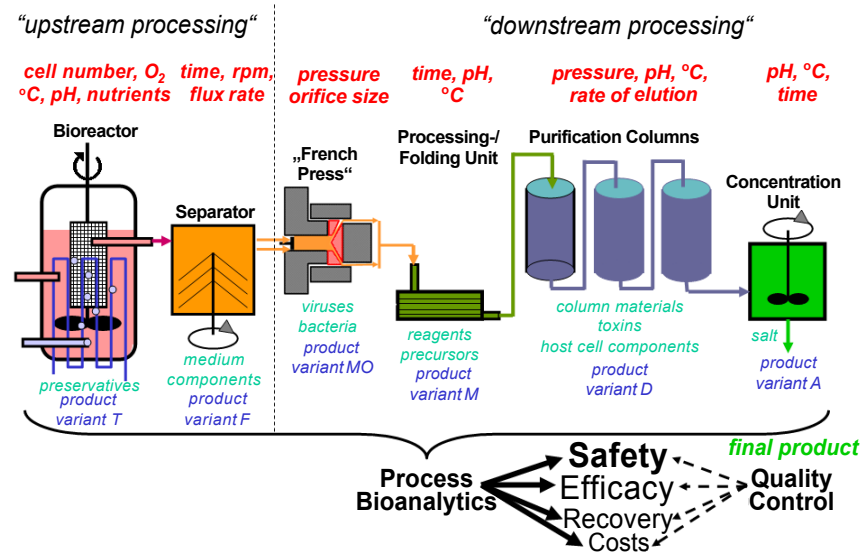

Figure 2: Process analytics as understanding of the relationship between process, product(-variants) and contaminants. During upstream and downstream processing, deviations from the optimal process parameters (in red) for each of the individual steps will lead to the emergence of the product variants $T, F, M O$, $M, D$, and $A$ (in blue, symbols see Figure 1) and contaminants (in green) which are difficult to detect in the final product by routine quality control. These may affect the production costs, recovery, efficacy and safety of the protein drug in differential fashion with safety being of highest importance. 
for the processing (e.g. enzymes) and precipitation (e.g. salt) steps (Figure 2). In consequence, at the end of the upstream and downstream processing the authentic protein product may often contain product variants and contaminants of varying nature and at variable amounts. In unfavourable cases the efficacy and safety of the protein drug may be negatively affected by the presence of product variants and contaminants in the final drug preparation.

Consequently, a deep understanding of the production process should encompass the relationship and interdependence of the relevant process parameters and the generation of the authentic protein, protein variants and contaminants under both optimal and sub-optimal running conditions (Figure 2). Thus, process analytics certainly exceeds the requirements for a mere analysis of the product, variants and contaminants with far-reaching consequences. In addition to the improvement of process control, this information will be required for the approval of a protein drug by the relevant health authorities, such as the EMA and FDA. For this, it is usually not sufficient to demonstrate the apparent purity of the final drug preparation. Instead, the manufacturer has to convince the authorities that (i) the production process envisaged will manage to generate a protein drug of the desired efficacy and safety in reproducible and reliable fashion, that (ii) any (critical) deviation of the production process from the optimal conditions will be recognized in time by the installed analytical devices and the data evaluation and that (iii) strategies are implemented that guarantee the rapid normalization of the sub-optimal process parameters for any critical step. Overall these demands for process validation, risk analysis and process control can be summarized with the statement "the process is the product". The consequences are farreaching with regard to the official rules for production (GMP), storage (GSP) and documentation (SOPs), for which general recommendations and instructions (PAT) have been worked out by the FDA (see below). This requirement for an understanding of the production-product relationship is unique for protein drugs so far as is exemplified by the moderate or even missing rules and international standards for the production of human and animal food.

\section{Hardware-Based Bioanalytics}

The bioanalytical tests and assays required and selected for "state-of-the-art" process analytics have to fulfill a number of criteria which are summarized under the terms, qualification, calibration and validation. In a typical bioanalytical test the analyte contained in the sample induces a specific signal, the so-called read-out, e.g. light, current, fluorescence or luminescence impulses, most often elicited by a specific instrument. By nature of the test and instrumental configuration, even in absence of the analyte a signal will usually be generated. This "background" or "noise" should be as low as possible and is subtracted from each analyte-induced signal. As internationally accepted rule the signal-to-noise ratio has to exceed the factor of three, i.e. the analyte-induced signal has to be three-fold above the "noise" to be accepted as "specific" value for the analysis. This threshold defines the sensitivity or limit of detection (lod) of the test for this analyte without the scope for its quantification. With increasing amounts of sample, i.e. analyte, the analyte-induced signal will increase in nonlinear fashion during a first phase, and then in linear fashion during a second phase. The lowest amount of analyte for which linearity holds true represents the lower limit of quantification (lloq). The slope of this line of direct proportionality should be high, resulting in pronounced increases in signal in response to rather low elevations in sample analyte and thereby defining the resolution of the test. At analyte concentrations exceeding the upper limit of quantification (uloq) any increase in the analyte will not result in a further linear elevation of the signal, but rather in gradually approaching a plateau phase. The start and end points of the linear phase between analyte concentration and signal define the dynamic "window", i.e. the range of measurable analyte concentrations, of the test. Certainly, this range should be as broad as possible for practical reasons, e.g. to avoid multiple sample dilutions prior to testing.

The test has to determine the analyte, e.g. human insulin, in very specific fashion, i.e. the ratio between the signals induced by the "active" (e.g. natively folded) sample analyte and the "inactive" (e.g. heatdenatured unfolded) reference analyte should be as high as possible. This ratio between the authentic "active" product and a more or less defective or interfering product variant defines the selectivity of the test. Furthermore, the reproducibility of the test is a critical factor and is affected by many different systematic and non-systematic errors, such as quality of the reagents, efficacy of the reactions involved, accuracy in pipetting, variation in instrumental data measurement, evaluation and calculation etc. By nature, distinct types of reproducibility can be discriminated, among them intra-assay variance, which encompasses measurements performed by the same operator with the same reagents, pipettes and instruments on the same day, and inter-assay variance, which characterizes measurements performed on different days by different operators using different pipettes, newly prepared reagents, independent reactions as well as distinct instrumentation, which may be switched off-on and recalibrated. Inter-assay variance will always exceed intra-assay variance, but reflect the conditions for analysis of upstream and downstream processing products at the industrial scale in more realistic and reliable fashion.

\section{Test Validation}

The expenditure for and the scope of the validation of a test are related to its purpose and application. Furthermore, an in-house procedure requires a less exacting process than a method intended for multi-matrix and/or multi-laboratory use. For the latter tests, a full collaborative trial is necessary. However, for many purposes validation is limited to either demonstrating that method performance criteria established during development are met under routine laboratory conditions and/or showing test equivalence. The United States Pharmacopoeia identifies three categories of test: (i) Bioanalytical tests for quantitation of major components of bulk drug substances or active ingredients (including preservatives), (ii) bioanalytical methods for determination of impurities in bulk drug substances or degradation products in finished biopharmaceutical products, (iii) bioanalytical tests for determination of performance characteristics (e.g. dissolution, storage, drug release). Relevant parameters for all three types include accuracy, precision, selectivity/specificity, lod, lloq, uloq, linearity, dynamic range and robustness. One of the unfortunate previous choices of nomenclature is the use of "specificity" where what is actually required is "selectivity". Few bioanalytical tests are specific for a given analyte but generally can be made sufficiently selective for the purpose.

After quantitative determination of each of these criteria they have to be transformed and integrated into an "overall" parameter for the validity of the test reflecting all criteria in combination, the so-called $\mathrm{z}$-factor. Calculated factors below or identical to 0.05 are regarded as indicative for a valid assay. However, it is of crucial importance to realize that there is no test validation as well as no validated assay per se, i.e. independent of the specific performance needs or purpose that have to be fulfilled by the test. For instance, validation of its resolution 
performance (see above) is critically dependent on the selection of the reference material(s) used and has to be justified toward the health authorities for drug approval. Furthermore, the reasons for the qualification of each test have to be presented to the authorities, including the arguments for the choice of the parameter analysed by the test, e.g. identity, structure, function. For instance, the validation of a test for the structure or function of a protein drug in comparison to a heat-inactivated material as reference may be useful if the emergence of the latter is conceivable in course of production of the drug.

\section{Test Qualification}

Analytical biochemists are by nature innovators and seekers of improvement. In the development area these qualities are invaluable in optimising the performance of a given method. However, far too often, this desire for continuous improvement spills over into the qualification of methods for process and quality control. Here consistency of application and rigorous control of processes and procedures have highest priority. These aspects are anathema for many practitioners of the "art of bioanalysis". Whilst this may be sustainable, albeit undesirable, for some applications within a single laboratory, discipline becomes a necessity when methods have to be transferred reliably between laboratories within an organisation or, even more critical, between distinct organisations. When the scope of operation encompasses different organisations, national boundaries, etc., uniformity of the approach is essential if comparable results have to be obtained. This discipline does not originate easily as it requires a control framework. The framework may be considered disturbing and unnecessary by some analytical biochemists, particularly those from a research environment. It is hoped to persuade those who doubt its necessity that the successful deployment of a method and its wide application rely heavily on such an approach and that flair, innovation and technical excellence alone are insufficient.

In general, the foundations for the confidence in a bioanalytical result require that (i) the sample is representative and homogeneous, (ii) the test selected is based upon sound scientific principles and has been shown to be robust and reliable for the sample analyte under test, (iii) the instrumentation used has been qualified and calibrated, (iv) a person who is both competent and adequately trained has carried out the analysis and (v) the data calculation is correct and statistically sound. Thus a control framework for the selection, development and validation of laboratory-based bioanalytical methods has to be established which includes both sample collection, preparation and storage (see above "i") and assay qualification (see above "ii-v"). Since many of the methods will be employed in generating data that could have profound legal or commercial impacts, the validity of bioanalytical results should be established beyond reasonable doubt. Importantly, validation of a bioanalytical test is not a single event. Rather it is a journey with a defined itinerary and stopping places as well as a final destination. The goal is a method that satisfies the original intent. A disciplined route is required which maps out both the qualification and validation process.

The key factors that need to be established for test qualification include (i) applicability of the bioanalytical principle(s) over the concentration range required, (ii) optimisation of the experimental conditions, (iii) selection of the calibration function, (iv) selection of the reference materials and standards, (v) evaluation of matrix effects and interferences, (vi) recovery experiments, (vii) robustness of the procedure toward changes in key parameters and (viii) generation of initial accuracy and precision data. The qualification procedure is likely to be an iterative one. However, it is essential that good written records are stored during this phase so that, in the event of problems at subsequent levels, investigations may be more readily carried out. However, far too often the excuse of "bioanalytical creativity" is cited for lack of such records. The most important outcome from this initial evaluation should be an assessment of the robustness of the developed test.

In general, it is critical if the test qualification is carried out by deciding to apply the method that is most popular or familiar. If a laboratory has expertise in a particular technique then is tempting it to use that expertise as the overriding factor for test qualification. Rarely is there a structured and rational approach for test qualification. Whilst it is often possible to make inappropriate methods work within a single laboratory, the impact on the reliable transfer between laboratories can be very large. In the past, the transferability of test methods has not been given the prominence it deserves. However, within the current climate of harmonisation and interchangeability, the technical requirements for test transfer and performance have been addressed in some detail. There are two areas which have received less attention and agreement, namely the inter-comparison of different tests for the same analytes inhouse or within a few laboratories and the methods for describing and writing analytical tests. No test is "fit for purpose" unless there are clear and unambigous written instructions for carrying out the prescribed testing in accordance with the conditions laid down in the original test developmental cycle. The literature contains examples of collaborative efforts that only prove that the test was not fit for its intended purpose. The full IUPAC harmonised protocol is by its very nature an extensive and expensive exercise. From an economical perspective such trials should only be undertaken when there is well-documented evidence for sufficient robustness of the method under evaluation. Investment of time and intellectual effort for test qualification and the other aspects of the user requirements specification will pay great dividends. Prevention is better and almost always cheaper than cure.

Once the "User Requirements Specification" has been drawn up and the method performance criteria set, the test development process can begin. Quite often there are existing tests available within the literature or within trade and industry. On many occasions it is tempting to ignore the difficulties of a comprehensive literature search to save time. However, as a minimum, key word searches through the primary literature and abstracting journals, such as Analytical Abstracts, should be undertaken. For standard tests, it is essential to scan international standards from Europe and the USA as well as local sources and those deriving from statutory publications. Once already existing tests have been identified, it is good practice to compare them objectively. One way to do this is to list the performance criteria and relevant section of the User Requirements Specification and tabulate the corresponding data. An existing test may have a sufficiently good fit that adaptation is likely to lead to a suitable method. This relies upon professional knowledge and experience. For tests that are likely to be widely used, other aspects of suitability need to be considered. Some areas for consideration are listed below: (i) Can the method be written down sufficiently clearly and concisely to allow ease of the transfer? (ii) Can all the critical test parameters be identified and controlled, which is particularly important if automated systems are involved? (iii) Is the equipment readily available to all the likely participants? This assumes a special importance for internationally distributed tests and may involve questions of maintentance and support. (iv) Are all the reagents and solvents readily available in the appropriate quality? (v) Do the staff have the requisite skills and training to carry out the procedure? (vi) Are health and safety or environmental considerations 
likely to cause problems? (vii) Are standards and reference materials readily available to ensure that equipment and test systems are properly selected and calibrated?

In addition to validity, numerous other crucial criteria have to be considered for the qualification of bioanalytical tests, among them (i) the costs for the technical equipment, reagents and consumables as well as for the operators, (ii) the robustness, i.e. inertness of the measurement and data generation toward matrix components, (iii) the sample volume to save the product as well as reagents required for the analysis, and (iv) the possibility for process integration. For the efficient and rapid control of the production process on the basis of determination of the relevant product parameters, such as amount, product variants and contaminants, the data have to be available as soon as possible, i.e. on-line a short period after sample delivery. In case of delayed correction of and/or compensation for the sub-optimal process parameters, the product parameters would further deteriorate. This could lead to a vicious cycle within a single processing step and between successive steps if product variants and contaminants introduced by an upstream step cause deviations from the optimal parameters in downstream steps.

For integration into the production process, the bioanalytical test(s) have to be coupled intimately to the production process, at best at on-line and real-time mode. These requirements lead to severe limitations in the time available for eventual sample preparation, sample injection, actual analyte measurement and data analysis. Moreover, the bioanalytical test has to handle a considerable number of samples which have been collected along the whole production process at each critical step. Finally, since "a single test is no test", it is strongly recommended to test for more than a single product parameter, including identity, amount, structure, function, immunogenicity, toxicity and contaminants, in parallel at best or, if not feasible, successively within a short period.

The test criteria discussed above hold true irrespective of the product parameter analysed which include methods for demonstrating the (i) molecular identity via mass spectrometry (Figure 3) [22,42-44],

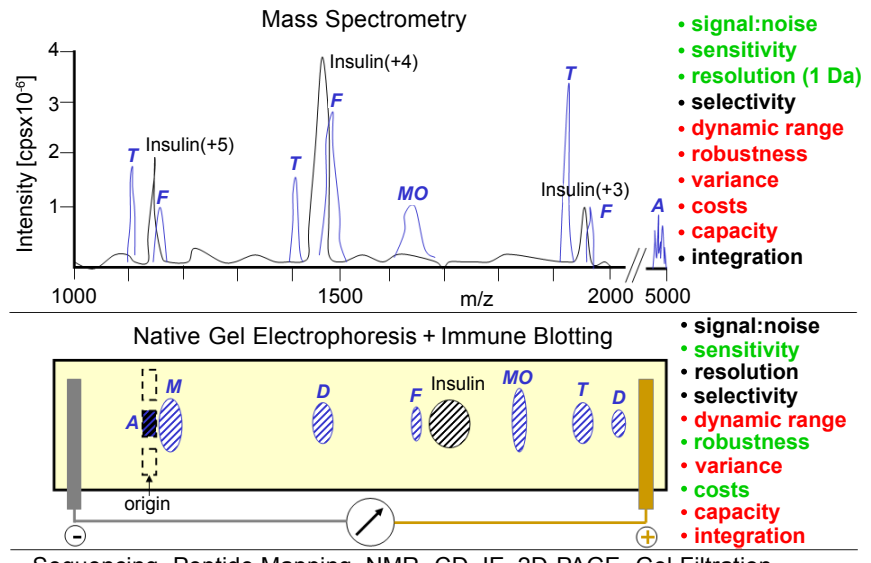

Sequencing, Peptide Mapping, NMR, CD, IE, 2D-PAGE, Gel Filtration

Figure 3: Bioanalytical tests for the parameters of molecular identity and structure. Advantages (in green), disadvantages (in red) and "neutral" criteria (in black) on the basis of the criteria for target qualification are given for mass spectrometry (nano-electrospray, MALDI-TOF, LC-MS/MS, $200 \mu \mathrm{M}, 22^{\circ} \mathrm{C}, \mathrm{pH}=4.0$, $\mathrm{Zn} 2+, \mathrm{Cl}-$ ) and native gel electrophoresis (polyacrylamide gel, urea, $20 \mu \mathrm{g}, \mathrm{pH}=$ 6.8 ) combined with immunoblotting (polyclonal anti-insulin antiserum, $16 \mathrm{~h}$ ) as exemplified for some insulin variants (symbols see Figure 1). Some alternative methods are listed at the bottom.

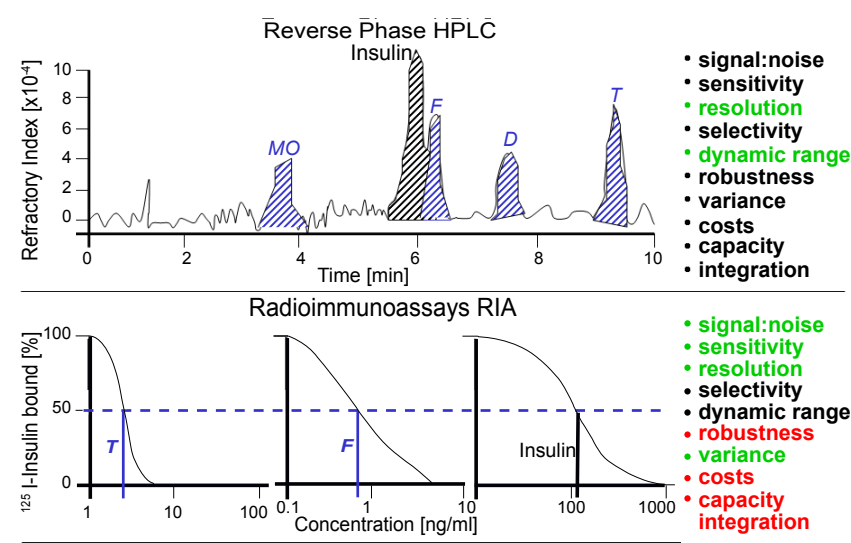

ELISA, colorimetry, quantitative amino acid analysis, $\mathrm{N}$,- determination

Figure 4 : Bioanalytical tests for the parameters of product amount on basis of physicochemical and immunological characteristics. Advantages (in green), disadvantages (in red) and "neutral" criteria on the basis of the criteria for target qualification are given for reverse phase HPLC (Eclipse XDB C8; 80A pore size, isokratic, $1 \mathrm{ml} / \mathrm{min}, 40 \mathrm{mM}$ sodium phosphate, $\mathrm{pH}=3.7,85 \%$ phosphoric acid, $24 \%$ acetonitril, excitation $276 \mathrm{~nm}$, emission 306) and radioimmunoassays (displacement curves with immobilised monoclonal antibody, $\left[{ }^{125}\right]$ insulin, SDStreated samples) as exemplified for some insulin variants (symbols see Figure 1). Some alternative methods are listed at the bottom.

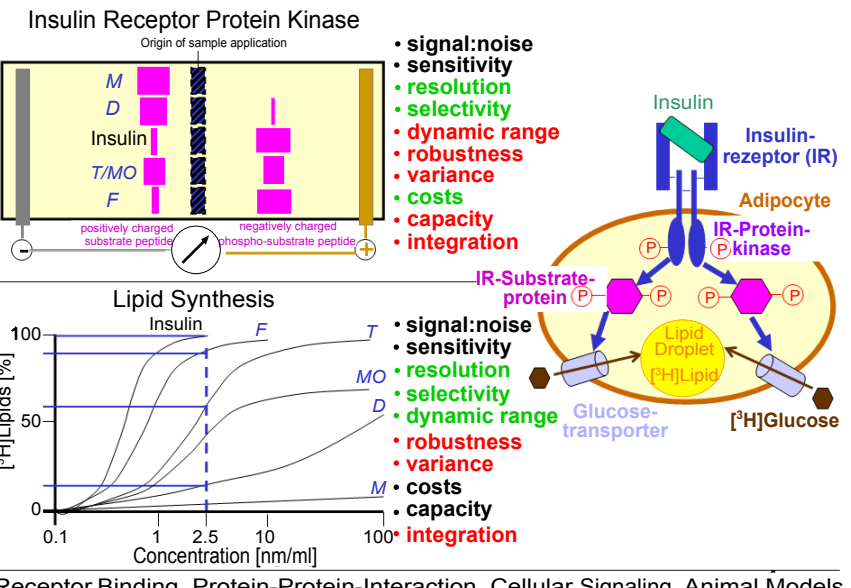

Figure 5: Bioanalytical tests for the parameters of molecular and cellular function. Advantages (in green), disadvantages (in red) and "neutral" criteria (in black) are given for assaying insulin receptor protein kinase activity (recombinant insulin receptor, fluorescent substrate peptide with consensus phosphorylation site, ATP, $0.8 \%$ agarose gel, $120 \mathrm{~V}, 55 \mathrm{~mA}, 20 \mathrm{~min}$, extraction and fluorometric quantification of phosphorylated fluorescent peptide) and lipid synthesis (insulin concentration-response curves with response at $2.5 \mathrm{ng} / \mathrm{ml}$ for each variant of the incorporation of $[3 \mathrm{H}]$ glucose into lipids in rat adipocytes, extraction and radiometric quantification of radiolabeled lipids) on the basis of the criteria for target qualification as exemplified for some insulin variants (symbols see Figure 1). Some alternative methods are listed at the bottom. The molecular basis for the activation of the insulin receptor protein kinase and lipid synthesis by insulin in adipocytes involving phosphorylation of the insulin receptor substrate protein in the cytoplasm and activation of the glucose transporter at the plasma membrane is depicted on the right.

(ii) two- and three-dimensional structure via native gel electrophoresis (Figure 3), Fourier-transformed infrared conformational analysis and circular dichroism [45-47], (iii) product amount via physicochemical (LC, 2D-NMR, RP-HPLC; Figure 4) [48,49] or immunological (radioimmunoassay; Figure 4) characteristics [1], (iv) function at the molecular (cell-free receptor or enzmye test; Figure 5) [50] or cellular 


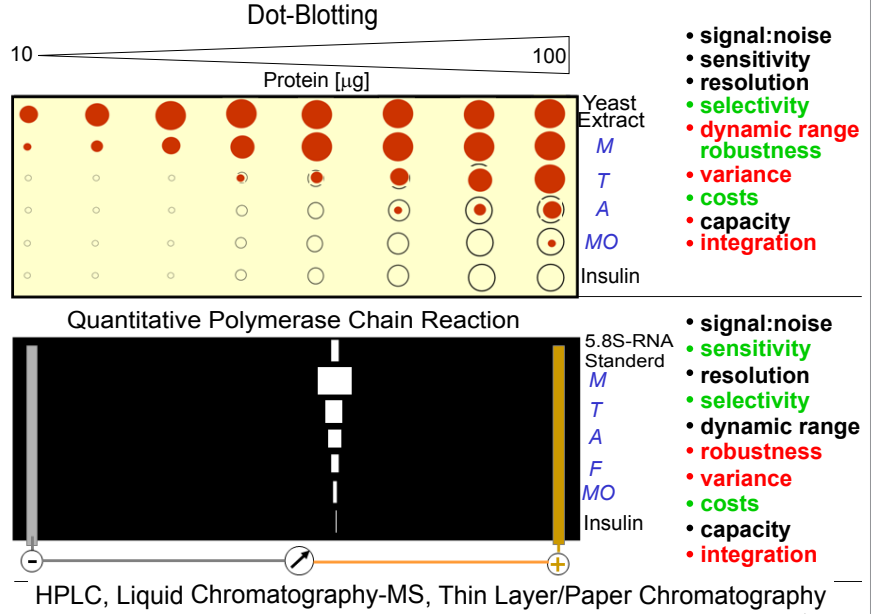

Figure 6: Bioanalytical tests for the parameters of endogenous contamination with HCPs and nucleic acids. Advantages (in green), disadvantages (in red) and "neutral" criteria on the basis of the criteria for target qualification are given for protein dot-blotting and quantitative polymerase chain reaction as exemplified for some insulin variants, which were produced in recombinant yeast cells (symbols see Figure 1), and extract from non-transfected yeast and 5.8S-RNA standard, respectively. Some alternative methods are listed at the bottom.

(cell-based physiological test; Figure 5) [50-53] level, (v) exogenous contaminants, such as toxins and antibiotics and (vi) endogenous contaminants, such as HCPs (dot blotting; Figure 6) or nucleic acids (RT-PCR; Figure 6) [54,55].

In conclusion, the qualification of tests to support validated, calibrated and approved process analytics along the whole biopharmaceutical production process necessitates high demands to be fulfilled by each test chosen as well as by each expert and operator involved [56,57]. It has to be accepted that most bioanalytical tests taken into consideration irrespective of the underlying principle will fail to meet all the requirements and represent compromises of numerous advantages and disadvantages [23]. The bioanalytics expert is responsible for the selection and creation of a test or test combination, which fits best to the process analytical task and, in most cases, represents an acceptable compromise. However, the design of any bioanalytical test is not "fixed in stone" and untouchable during subsequent periods of time. Rather the design has to be adapted to the current "state-of-the-analytical art" with regard to the technological progress as well as the gain in scientific knowledge about the putative pathophysiological relevance of the product variants and contaminants. This may necessitate the implementation of novel appropriate tests or the improvement of the sensitivity of already established ones in accordance with the rules and requests put forward by the health authorities.

\section{Protein Chips - the Principle}

During the last decade a large body of evidence has accumulated that protein chips may revolutionize the area of process analytics in biopharmaceutical production by their intrinsic capability of rapidly and simultaneously handling many samples under fulfillment of the criteria of validity, robustness, miniaturization and relatively low costs. Moreover, after special adaption they also enable multi-parameter analysis. Moreover, protein chips can not only be used for the evaluation of polypeptides of any size but also for the determination of small nonpeptidergic analytes, such as lipids, carbohydrates and intermediary

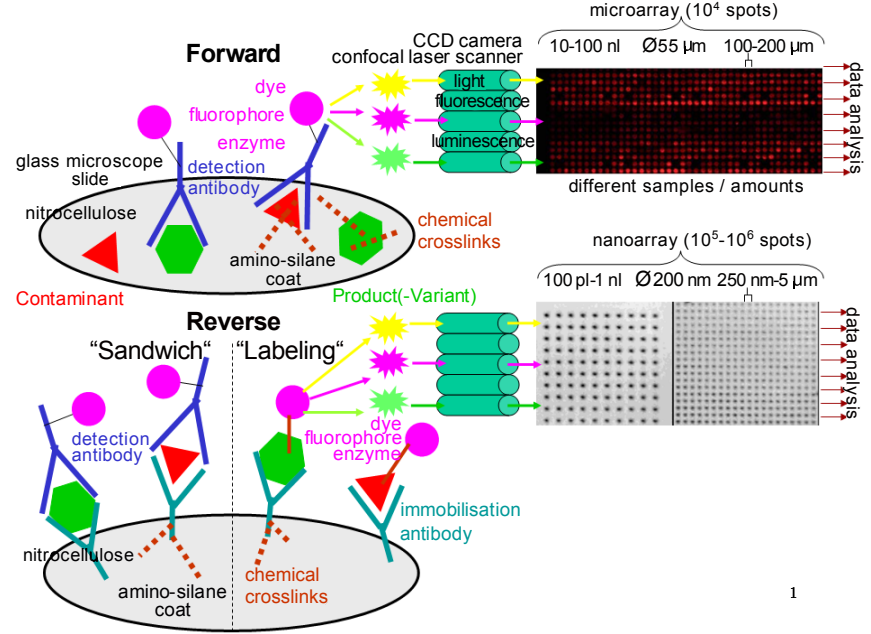

Figure 7: Principles of protein chip operation. The two distinct modes-of-action rely on either the direct (Forward) or indirect (Reverse) immobilisation of the protein analytes, such as products, product variants and contaminants, to the glass microscope slide by their non-covalent and chemical crosslinking or binding to immobilised antibodies, respectively. The protein analytes are subsequently detected by labeled antibodies in the "sandwich" or by labeling of the analytes in the "labeling" configuration. Read-out is identical for all modes and configurations and compatible with the micro- and nanoarray formats.

metabolites [56-64]. These characteristics considerably broaden the application profile of protein chips from mere biotechnological process analytics to novel biomedical research areas in diagnostics, drug discovery and biomaterial sciences, (i) personalized medicine with its scope of individualized diagnostics and therapy, (ii) systems biology with its aim of understanding the pathophysiology of common multifactorial diseases at the level of cells, tissues and the total organism including the interacting signaling cascades and metabolic networks, and (iii) tissue engineering with its potential to provide functional organs differentiated in vitro from (e.g. adipose tissuederived) mesenchymal stem cells which had been isolated from the corresponding patient.

The mode of operation of protein chips, which are based on polypeptides rather than on nucleic acids as is the case for DNA/gene chips, can be easily explained (Figure 7). Protein chips, also known as protein microarrays, are miniaturized parallel assay systems which harbour minute amounts of highly purified proteins immobilised in a high-density format. They enable the simultaneous measurement of a variety of bioanalytes from limited amounts of complex sample mixtures in a single run. Initial approaches to simultaneously analyse large numbers of proteins for various parameters, such as molecular identity, amount, structure or function, were based on spotting down bacterial strains or bacterial total lysates of cDNA-driven protein expression libraries on nylon membranes [59-62,65-67]. A major progress was then the fabrication of protein chips consisting of 5,800 single yeast proteins on a specifically modified microscope glass slide [58]. Subsequently, a variety of useful applications, such as the identification of target proteins of small drug molecules, substantiated the practical value of protein chips.

Many protein chips are fabricated by the immobilisation of proteins onto a microscope glass slide with the help of a standard piezoelectric contact $[68,69]$ or non-contact microarray printer [70-72]. Different slide surfaces are in use, including aldehyde- and epoxy-derivatized 
glass surfaces, so-called "Fullmoon" slides, or "Schott" NHSderivatized slides for random linkage of the proteins through amines $[69,73]$, nitrocellulose- $[74,75]$ or gel- $[76,77]$ coated slides for coupling through diffusion and absorption as well as nickel-coated slides for the non-covalent binding of His6-tagged proteins. In any case the immobilisation step has to operate in efficient, reliable and quantitative fashion. This means that each polypeptide contained in the sample has to be retained at the chip surface in quantitative fashion, irrespective of its nature and abundance. Furthermore, the nature of the interaction of the individual sample polypeptides with the chip surface, i.e. the type and number of the amino acids involved in cross-linking or secondary bond formation, is heterogeneous and can hardly be predicted. This may lead to variable and non-quantitative immobilisation. After successful immobilisation onto the slides, the proteins are evaluated for diverse parameters that classify the protein chips into two categories, analytical ones for the elucidation of the molecular identity, structure or amount and functional ones [76-84].

\section{Forward Protein Chips}

For the analysis of the identity, structure and/or amount of the protein drug or the detection of protein variants or contaminants, the protein chip becomes incubated with an appropriate well-characterized molecular probe which often is a specific antibody [85,86] (including single-chain or other variants), but nowadays instead may also consist of peptide-major histocompatibility complexes, carbohydrate-binding lectins, protein-interacting anti-/lipocalins, protein-nucleic acids or RNA aptamers. For the demonstration of binding of the molecular probes to the chip surface, they are coupled to a dye, a fluorophore or an enzyme which catalyzes a luminescent reaction. The light, fluorescence or luminescence signals are detected by a multi-channel laser scanner or CCD camera with high resolution power. The resulting typical patterns of (directly or indirectly) colored spots in regular arrangement (Figure 7) are evaluated for spot intensity, with the more intense, the higher the amount of the probe bound to the chip, the higher the amount of analyte immobilised onto the chip surface, the higher the analyte concentration of the sample. Data generation encompassing the incubation of the chip with the probe, the binding of the probe to the analyte, the washing of the chip for removal of unbound analyte, the reading-out of the chip for spot intensity and the computer-based data transformation and the calculation of the actual analyte concentration requires short periods of time only (e.g. $120 \mathrm{sec}$ for a single cycle). The number of samples that can be processed in parallel depends on the power of the automatic chip printer used which generates spots of defined diameter and in defined distance from one another. With the currently available microarrays up to 10E4 spots can be applied onto a typical light microscope glass slide. Future nanoarrays will enable the spotting of up to 10E6 samples per slide with spot diameters as small as $250 \mathrm{~nm}$, and will be limited only by the resolution of the available scanners. Thus, in principle, protein chips seem to meet the major bioanalytical demands, i.e. the measurement of many samples in parallel in short time with the option of multi-parameter analysis and automation.

With regard to functional protein chips, a large number of proteins in case of complex biological samples or the total proteome of a cell or organism in case of a systems biology approach are spotted. There is no need for extensive biochemical characterization of the proteins prior to immobilisation and chip analysis. The systematic screening for specific and divergent activities and functions may encompass protein-protein, protein-DNA, protein-carbohydrate, protein-lipid, protein-metabolite and protein-drug interactions as well as the identification of enzyme substrates or the detection of (undesired) immune and toxicological responses. The formats of the protein chips currently used vary considerably to match the diverse requirements from high-throughput analysis of routine parameters to the huge spectrum of low-throughput analysis of more specific functions.

Importantly, this type of forward protein chip critically depends on the quantitative immobilisation of the protein analytes by secondary bonds or covalent cross-links at the chip surface as well as their quantitative detection by the labeled molecular probes, such as antibodies. However, even in case of quantitative recovery of the analytes, it can not be excluded that unspecific interactions and modifications involved herein will lead to masking of certain protein epitopes which are recognized by the detecting probe. By nature, the amino acids involved in the interaction of the protein analyte with the chip surface as elicited by a selected procedure is difficult, and sometimes even impossible, to predict and may vary with each cycle of immobilisation. As a consequence, the detection of the analyte will not be quantitative leading to underestimation of the analyte concentration with considerable variation between distinct measurements.

\section{Reverse Protein Chips}

To circumvent these problems the so-called reverse protein chip has been introduced which relies on immobilisation of the protein analytes by binding to well-characterized immobilising probes (Figure 7). This type of analytical or functional protein chip represents the most convenient and powerful multiplexed detection platforms and is commonly used for determining protein expression, profiling cell surface markers, identifying biomarkers, and measuring diagnostic factors. The immobilising probes, most often antibodies, are themselves coupled onto the chip surface by secondary interactions with a (e.g. nitrocellulose) coat or by covalent cross-linking to functional (e.g. amino) groups of the glass slide [87-90]. In contrast to forward chips with their direct immobilisation of the protein analytes by the same means, the reverse chips can be controlled and normalized for the coupling efficacy of the immobilising antibodies under standard conditions to compensate for eventual non-quantitative recovery of the protein analytes. This solely depends on the number of functional immobilising antibodies coupled to the chip surface. For detection of the protein analyte, the so-called "sandwich" configuration relies on the specific binding of a 2nd antibody that recognizes an epitope distinct from the immobilising 1st antibody and is labeled with a dye, fluorophore or luminsecent enzyme. In consequence, "sandwich" protein chips have the advantage of exquisite selectivity for the protein analyte due to the simultaneous operation of two different antibodies. However, the identification of a pair of antibodies directed against the protein analyte, which are specific for distinct non-overlapping epitopes and do not mutually impair binding to the analyte due to steric hindrance, is often tedious, long-lasting and expensive and sometimes may even fail. However, the putative (partial) incompatibility of 1 st and 2nd antibodies will be recognized in time during the chip development. Nevertheless, in some cases compensation for partial interference by normalization may be feasible and useful, since the same antibody pair can be used throughout the chip analysis. Thereby, underestimation and high variance in the determination of the analyte content would be minimized by the "reverse sandwich" chip. At variance, the "direct labeling" configuration circumvents the need for a 2nd detecting antibody (and, in consequence, may be of lower selectivity than the "sandwich" chip). For this the dye, fluorophore or enzyme is coupled to the protein analytes through secondary interactions or covalent crosslinking prior to incubation of the samples with the protein chip. 


\section{GPI-Protein Chips}

Unfortunately, the technologies of both "forward" and "reverse" protein chips described above could lead to non-quantitative detection and immobilisation, respectively, of the (indirectly and directly tagged) analytes in course of (partial) masking of the epitopes recognized by the immobilising antibody/anticalin and detecting antibody, respectively. In consequence, these conventional protein chips are faced with formidable challenges in the quantitative detection and immobilisation, respectively, of the protein analytes. The problems may be (partially) overcome by a novel type of protein chip that is based on glycosylphosphatidylinositol- (GPI-) anchored proteins (GPI-proteins). These GPI-protein chips are currently being evaluated and validated for numerous applications in process analytics for the biopharmaceutical production, in "point-of-care-testing" for individualized diagnostics and health care as well as in drug discovery and compound optimisation.

Typical transmembrane proteins span the phospholipid bilayer of the cellular plasma membranes through a single or several stretch(es) of hydrophobic amino acids, the transmembrane domain(s), with large amino-terminal (carbohydrate- and disulfide bridge-harbouring) and carboxy-terminal polypeptide domains facing the cell surface and protruding into the cytoplasm, respectively. In contrast, GPIproteins lack (a) transmembrane domain(s) but are embedded exclusively in the outer extracellular leaflet of the phospholipid bilayer by a covalently linked GPI structure [91-93]. This glycolipid anchor consists of phosphatidylinositol and several distinct and specifically linked carbohydrate moieties, the glycan portion, and is coupled via its terminal ethanolamine residue through an amide linkage to the carboxy-terminus of the extracellular protein domain. Thus, none of the amino acids of the GPI-protein moiety is in intimate contact to the plasma membrane. Rather, the GPI-protein is located at the cell surface solely through its GPI anchor, which can be specifically cleaved by phospholipase $\mathrm{C}$ leading to release and solubilisation of the protein moiety. GPI-proteins are expressed in all eucaryotic cells studied so far,

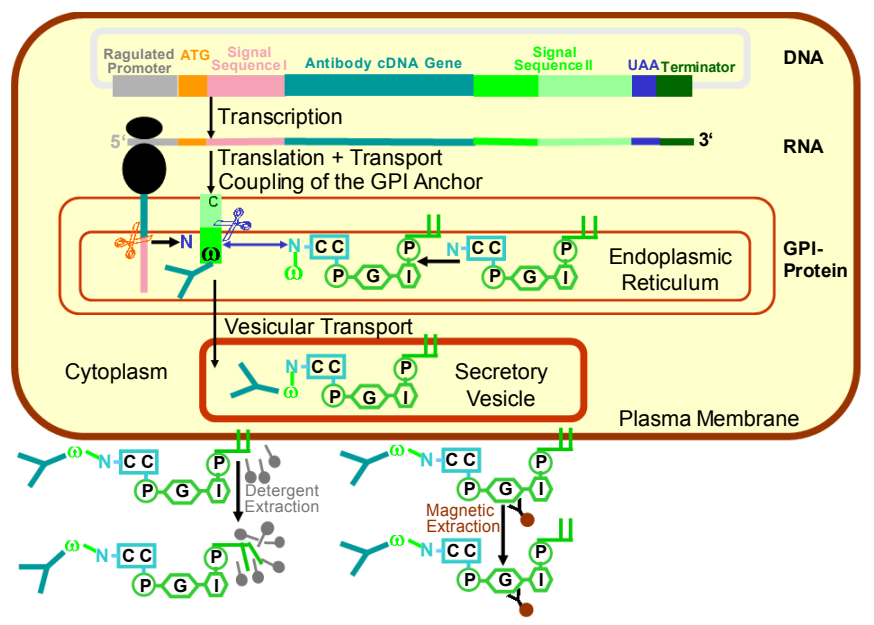

Figure 8: Recombinant production of GPI-proteins in eucaryotic cells. Soluble proteins, such as antibodies and protein drugs (e.g. insulin), are ectopically expressed as GPI-proteins in eucaryotic host cells in course of their plasmid-driven transcription, translation and co-translational translocation into the endoplasmic reticulum with concomitant coupling of the pre-fabricated GPI anchor to the carboxy-terminus of the protein domain and final transport to the outer surface of the plasma membrane along the classical secretory pathway. The GPI-proteins are then purified from the surface of the intact cells by detergent or "magnetic extraction". from yeast to man, and fulfil diverse functions as cell surface receptors, enzymes, antigens, transporters and signaling and adhesion molecules [92].

For application in the protein chip technology, it is most critical that in principle each soluble passenger protein, such as a binding protein, receptor, anticalin or antibody, can be expressed ectopically as GPI-protein at the surface of eucaryotic host cells, such as the yeast S. cerevisiae, chinese hamster ovary cells or human embryonic kidney cells, using recombinant DNA technology (Figure 8). For this, the relevant host cells have to be transfected with a plasmid harbouring the cDNA derived from the corresponding protein gene and appropriate 5 '- and 3'-regulatory elements for its inducible/repressible transcription and translation. In addition, for biogenesis of the passenger protein as GPI-protein two targeting signals, signal sequences I and II have to be placed at the 5'-/amino- and 3'-/carboxy-termini of the corresponding gene/protein constructs [94]. Signal sequence I directs the nascent GPIprotein through the endoplasmic reticulum and secretory vesicles to the plasma membrane along the typical secretory pathway. Simultaneously signal sequence II drives the covalent coupling of the GPI anchor, prefabricated in the endoplasmic reticulum by step-wise glycosylation of phosphatidylinositol, to the GPI-protein precursor in the course of removal of signal sequence II by a transamidase reaction occurring in the endoplasmic reticulum. The molecular machinery including the genes involved as well as the structural features of the signal sequences I and II have been elucidated during the past two decades [95-97]. This knowledge will be helpful for the ectopic expression of GPI-anchored versions of any soluble protein at the surface of host cells, in particular by engineering of optimised signal sequences as well as molecular components of the GPI-protein synthesis pathway [98].

\section{Recombinant Production of GPI-Proteins/Antibodies}

After the upstream processing, which includes fermentation of the recombinant host cells in a bioreactor and subsequent removal of the culture medium, total GPI-proteins will be extracted from the cell surface, preferably without solubilization of the cells. For this, nonionic detergents, such as Triton X-100, Triton X-114, octylglucoside, are added at low concentration at low temperature. This results in disintegration of the host cell plasma membrane under concomitant aggregation of the GPI-proteins together with cholesterol and (glyco-) sphingolipids into so-called lipid rafts [99], that can be collected and enriched by sucrose gradient centrifugation on basis of their low buoyant density. Finally, the GPI-proteins are solubilized by high concentration of octylglucoside at room temperature and, if required, further purified by (several rounds of) conventional column (preferably affinity) chromatography.

An alternative to this controlled detergent extraction has recently been developed, the so-called "magnetic extraction" (Figure 9). It is based on antibodies which are directed against the glycan portion of the GPI-protein anchor and covalently coupled to metal beads with diameters in the $\mu \mathrm{m}$-range [100]. Since the structure of the glycan portion is highly conserved and identical from yeast to man, these antiGPI antibodies, once raised and demonstrated to be of high affinity and selectivity, are used for the "magnetic extraction" of any GPI-protein produced in any host cell. For this the recombinant host cells, such as yeast or cultured mammalian cells, have to be immobilised or adherent, respectively, to the bottom of the culture dish of the bioreactor. Upon successful plasmid-driven cell surface expression of the GPI-proteins, such as protein drugs or antibodies for protein chips, the anti-GPI antibodies coupled to metal beads are added to the culture medium. 
Thereafter, an electromagnetic plate is positioned in the bioreactor in very close distance, however without direct contact, to the cell surface. Upon activation of the electromagnetic field and concomitant exposure of the cells to ultrasonic treatment, the magnetic plate is rapidly removed from the cell surface. This tightly controlled movement, which is performed by a high-precision robotic arm, causes the spontaneous displacement of the GPI-proteins, which are bound via the anti-GPI antibodies and the attached metal beads to the electromagnetic plate, from the lipid rafts of the host cell plasma membrane. Importantly the host cells will survive this procedure and can be re-used for the next fermentation cycle upon supplementation of fresh culture medium and re-induction of the GPI-protein expression system.

After washing of the electromagnetic plate with high concentrations of salt and low concentrations of non-ionic detergent to get rid of unspecifically associated medium and cellular components, the bound GPI-proteins are highly enriched toward plasma membrane (and total cellular) proteins since the major portion of them lacks the GPI anchor including its glycan moiety and therefore resists the "magnetic extraction". If required, the GPI-proteins bound to the antiGPI antibodies can be purified to homogeneity, i.e. separated from endogenous host cell proteins, after release from the electromagnetic plate. For this, the well-established techniques of magnetic filtration and purification on the basis of the metal beads associated with the GPI-proteins alone or in combination with Triton-X114 partitioning and classical chromatographic procedures will be useful. The final desorption of the GPI-proteins from the anti-GPI antibodies and/ or the electromagnetic plate are achieved by the addition of excess of carbohydrate, which competes for typical glycan components of the GPI anchor, such as mannose, or GPI anchor-cleaving bacterial phospholipase $\mathrm{C}$, which leaves the passenger protein with a phosphoinositolglycan moiety attached (lacking diacylglycerol). The strategy preferred depends on the requirement for the passenger protein with either the intact GPI anchor (e.g. GPI-antibody/analyte for protein chips, protein drug for oral application $[134,135]$ ) or (partially) deleted GPI anchor (e.g. GPI-protein as protein drug for non-oral application). In the latter case the complete removal of the GPI anchor is desirable and this necessitates the cleavage off of the residual phosphoinositolglycan moiety by specific phosphatases and exoglycosidases (Figure 9). Meanwhile the "magnetic extraction" process has been successfully applied for the large-scale production of GPI-anchored antibodies for protein chips as well as protein drugs, such as human insulin. This pilot bioreactor uses an automatically and continuously operating assembly line for the successive fermentation, extraction, purification and desorption steps of the GPI-proteins and the integrated recycling of the anti-GPI antibodies [100].

\section{Operation of GPI-Protein Chips}

For the immobilisation of the GPI-antibodies at the chip surface, the microscope glass slide is coated with a monolayer of phospholipids, which is facilitated by hydrophobic interactions between the saturated long-chain fatty acids and the glass surface and mimics the structure of the extracellular leaflet of the plasma membrane phospholipid bilayer. Upon addition of the anti-analyte GPI-antibodies embedded in detergent micelles to the phospholipid-coated glass slide, the antibodies become spontaneously inserted into the phospholipid monolayers solely triggered by dilution. This can meanwhile be managed with sufficient reliability by adapted automated standard printers commercially available for the spotting of conventional protein chips and will result in defined orientation of the GPI-antibodies with the antigen-binding domain facing the chip surface at high density.
The interaction resembles that of GPI-proteins reconstituted into the outer face of biological membranes upon their incubation with intact cells, liposomes or model membranes [101-104]. In comparison to covalent crosslinking, the GPI anchorage of the anti-analyte antibody to this special type of "reverse" protein chip has the advantage of being efficient and selective and causing lower background due to unspecific adsorption of the analyte. This often represents a problem with bifunctional chemical crosslinkers due to their hydrophobic nature and broad specificity. Moreover, the covalent coupling of the GPI anchor to the carboxy-terminus of the heavy chain of immunoglobulins or single-chain antibodies does not interfere with antigen recognition by the amino-terminal variable domains of their light (and heavy) chains, in general. This will guarantee high efficacy, robustness, reliability and reproducibility of the analyte immobilisation resulting in low variance between different measurements using the same chip or different chips, which have been prepared by different spotting procedures with different batches of anti-analyte GPI-antibodies.

Upon implementation of the required tools and equipment, the expenditure for the generic production of the anti-analyte GPIantibodies and their immobilisation onto the chip using versatile cassette GPI-protein expression vectors (Figure 8), "magnetic extraction" (Figure 9) and an automated standard printer for embedding into the phospholipid monolayer is usually lower compared to covalent crosslinking with regard to both time and costs. Crosslinking requires intensive testing of a multitude of chemicals and reaction conditions and careful quality control for successful coupling of functional antibodies to the chip surface. Upon addition of the sample to the GPI-protein chip, the immobilised analyte is routinely detected by binding of an anti-analyte antibody labeled with a dye, fluorophore or luminescent enzyme, as is the case for conventional reverse protein chips of the "sandwich" mode. This directly leads to corresponding light, fluorescence or luminescence signals at "positive" spots of the array.

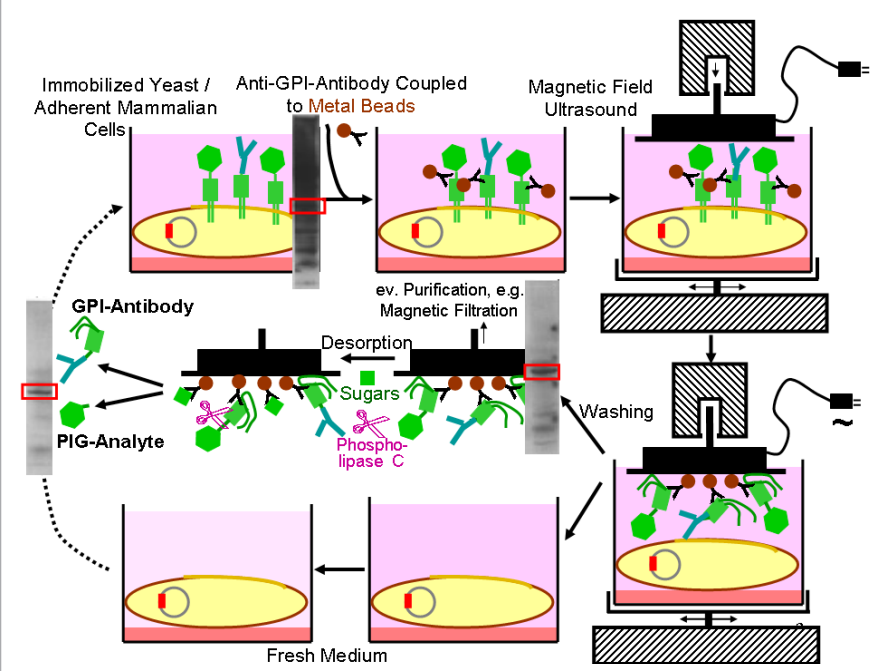

Figure 9: "Magnetic extraction" of GPI-proteins. GPI-proteins, such as antibodies and protein analytes, are extracted in the large scale by binding to anti-GPIantibodies coupled to metal beads and subsequent removal of the complexes formed between them and the GPI-proteins from the host cell surface by attraction to an electromagnetic plate. Upon lifting of the electromagnetic plate, the highly enriched GPI-proteins are released with the intact GPI anchor by excess of sugar moieties or as phosphoinositolglycan (PIG)-analytes (with PIG remnant) by cleavage with phospholipase $\mathrm{C}$. 


\section{Nanoparticle-Based (GPI-) Protein Chips}

Faced with the problems of the identification of (pairs of) capturing/ immobilising probes, most often monoclonal or polyclonal antibodies, as the most critical requirement for the development of sensitive and specific protein chips, intensive attempts have been made during the past decade to introduce alternative types of protein chips which (i) operate in solution rather than in solid phase, (ii) do not rely on specific capturing molecules, i.e. antibodies and (iii) do not require labeled detecting molecules, i.e. antibodies. These techniques take advantage of nanoparticles (NPs) and soluble reporter enzymes [105-110]. The reporter enzyme, such as bacterial $\beta$-galactosidase, has to catalyze an easily detectable reaction and preferably should exhibit a large surface area with exposed polar as well as hydrophobic amino acid side chains and/or post-translational modifications of complex nature and be monitored by simple photometric or amperometric (e.g. ISFET) [111114] measurement. $B$-Galactosidase is characterized by a negative net surface charge at physiological $\mathrm{pH}$. It was converted into its GPImodified version in order to increase its apolar surface area without significantly reducing its high solubility or causing its aggregation by recombinant expression in mammalian host cells (e.g. HEK-293, $\mathrm{CHO})$. Subsequently it was purified using "magnetic extraction" (see Figure 9). In contrast to the wildtype form, GPI- $\beta$-galactosidase displays amphiphilic character. This is caused by the carboxy-terminal GPI anchor harbouring two saturated long-chain fatty acids and the glycan moiety, which protrudes from the core of the polypeptide chain onto its surface, in combination with the negatively charged surfaceexposed amino acids. Importantly, the GPI modification does not significantly impair the hydrolytic activity of $\beta$-galactosidase.

The NPs used will replace in a certain sense the antibodies and serve as "chemical noses or tongues". They should manage to "smell or taste" the surfaces of the reporter enzyme and protein analyte in a very differentiated fashion [109]. For this, the NPs consist of a gold core and an outer shell of covalently coupled organic molecules. These shell structures are built by a terminal positively charged ammonium residue with one variable functional group of different hydrophobicity as substituent. In consequence, they may bind with high selectivity and avidity to protein surfaces through electrostatic and hydrophobic/ apolar interactions. In case of GPI- $\beta$-galactosidase, its surface will be recognized by these cationic/hydrophobic NPs via salt bonds between the terminal ammonium groups and the negatively charged amino acids as well as via hydrophobic interactions between the functional groups and the GPI fatty acids. Coverage by the NPs of GPI- $\beta$-galactosidase causes its complete blockade, for instance through binding to its glucose substrate-binding site. Upon simultaneous incubation of protein analytes with the GPI-B-galactosidase and the NPs, the analytes may fail to interact with the NPs thus leaving the reporter enzyme in the NP-bound and inhibited state. Alternatively, the analytes may succeed in interacting with the NPs and thereby displace them from the reporter enzyme thus relieving it from inhibition. The resulting activity signals will reflect the relative strength of the interactions between the NPs and the reporter enzyme vs. the protein analyte. They are positively and negatively correlated to the efficacy of the "smelling or tasting" of the surface characteristics of the protein analyte and GPI- $\beta$-galactosidase, respectively, by the NPs. Certainly a single type of NPs will enable only limited differentiation between different protein analytes contained in complex sample mixtures. It makes the combination of different types of NPs, each of them equipped with distinct functional groups that allow the unambiguous discrimination of a given analyte out of a complex biological sample. Taken together, protein chips based on NPs rather than antibodies seem to have the potential for sensitive, quantitative, selective and reliable determination of protein analytes from complex sample mixtures [110,115-117].

As a consequence, the generation of data signatures characteristic for the desired protein analyte in a complex sample, relies on multiple successive cycles with distinct types of NPs. The number of cycles will depend on the discrimination power of the NPs used, the nature of the analyte and sample as well as the specificity and resolution criteria desired for the assay. The multi-cycle handling of the microtiter plates, if performed manually, would considerably impede the rapid measurement of many samples with a multitude of different NPs. This delay would interfere with the requirements of process analytics during biotechnological production. To overcome this issue, the NPbased "smelling and "tasting" technology has been transferred from the microplate to the chip format that is based on a continuous flux of carrier fluid driving the components involved, such as buffers, samples, NPs, reporter enzyme and dye, from the corresponding reservoir chambers, which are integrated into a glass/silicon monolith, via microfluidic channels into the reactor. The basic principle including the electronic circuits and chips, which control the order of events through the regulation of microvalves are the same as described previously for the (GPI-) protein "chip-on-the-chip" [118]. However, here the reactor is just a temperature-controlled incubation chamber that becomes filled with binding buffer, reporter enzyme, NPs, sample and dye in defined order. The dye formed during the incubation is then measured in a distinct detection unit equipped with a photometer and installed at the efflux channel. Alternatively, the use of reporter enzymes leading to the formation of protons, such as glucose oxidase, can be simply monitored by a biosensor based on the technology of the ion-sensitive field effect transistor (ISFET) [111-114].

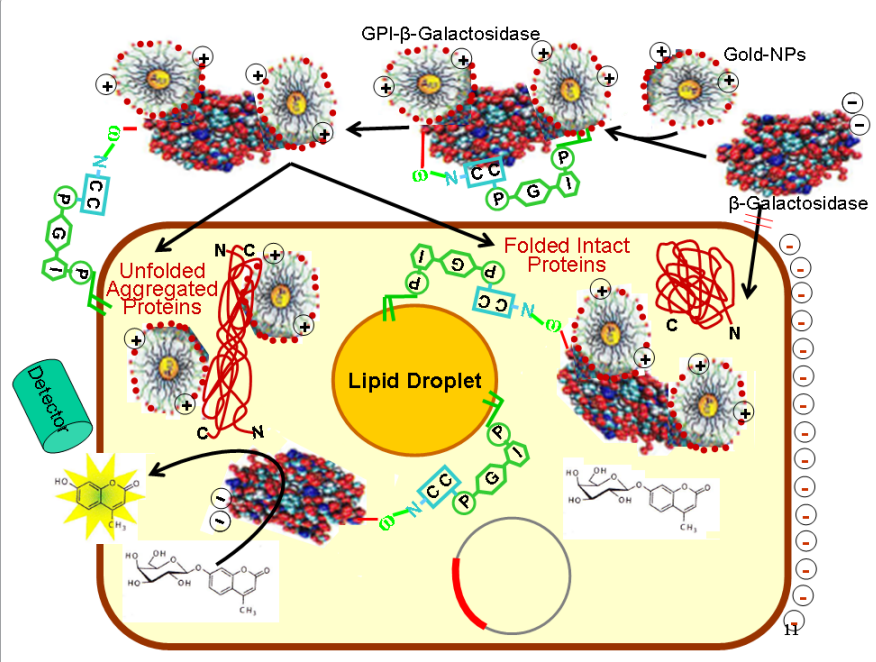

Figure 10: Principle of the NP-based cell chip. Upon interaction of the negatively charged reporter enzyme, GPI- $\beta$-galactosidase, with cationic hydrophobic gold-NPs, the positively charged complexes consisting of NPs and GPI- $\beta$ galactosidase come into contact with the outer leaflet of the plasma membrane bilayer and are subsequently translocated to the surface phospholipid monolayer of the cytoplasmic lipid droplets. Upon arrival at the cytoplasm with accumulated correctly folded or aggregated misfolded polypeptides, the NPs either remain bound or are relieved from binding to the GPI- $\beta$-galactosidase. The resulting inhibition or activation, respectively, of GPI- $\beta$-galactosidase is monitored as light generation and indicative for the amount of ectopically expressed passenger protein drug in the recombinant host cells that differs in structure from the authentic product. 


\section{Nanoparticle- and GPI-Protein-Based Cell-Based Assays}

The "chemical noses and tongues" constituted by NPs can even "smell and taste" within intact cells (Figure 10). For instance misfolded and denatured proteins as might be generated in course of the biotechnological production of recombinant proteins in response to stress of the host cells during suboptimal upstream processing (see Figure 1) have to be detected by process analytics in sensitive fashion. However, the study of the synthesis of protein drugs in the host cell in vivo, for instance under stress conditions during the largescale fermentation process, has turned out to represent a formidable challenge. For the corresponding application of the "chemical noses and tongues", the reporter enzyme has to be delivered into the cytosol of the cell to be monitored. Although some proteins can enter cells by receptor-mediated endocytosis, the majority is not recognized by appropriate cell surface receptors. However, some proteins lacking cell surface receptors have an intrinsic ability or are amenable for modifications to gain entry into the cytosol [119]. For instance, certain pancreatic-type ribonucleases readily undergo endocytosis and exhibit specific toxicity towards cancerous cells by degrading their RNA [120]. Binding of these ribonucleases to the cell surface is known to be unsaturable and mediated by non-specific ionic interactions. In particular, onconase, an $11.8 \mathrm{kDa}$ pancreatic-type ribonuclease possessing endogenous anti-tumoral activity and cytotoxicity, becomes internalized at a rate being only slightly faster than fluidphase uptake [121,122]. In contrast, natural cell-penetrating peptides, such as HIV-TAT or penetratin, are characterized by an abundance of cationic residues and endocytosed readily [119-125]. Interestingly, lysine and arginine residues are prerequisite for the internalization of those peptides which is presumably due to stable interactions with the carboxyl, phosphoryl and sulfuryl groups on the cell surface, thereby triggering endocytosis. In fact, increasing the net positive charge of a protein by either chemical modification or site-directed mutagenesis has been shown to increase its internalization [126]. For example, green fluorescent protein is a highly anionic protein that is not taken up by cells. Replacing five acidic residues with arginine on the surface of the folded green fluorescent protein endowed it with the ability to undergo endocytosis [120-122]. Installing even more cationic residues generated a variant that not only undergoes endocytosis, but also is capable to internalize passenger polypeptides. The efficacy of the internalization has been linked to (i) the net positive charge of the protein, (ii) the distribution of the charge over the protein surface and (iii) the type of positively charged amino acid involved, with arginine apparently being more potent than lysine residues $[125,126]$.

\section{Mode-of-Action}

The reporter enzyme, $\beta$-galactosidase, with its negatively charged surface at physiological $\mathrm{pH}$, is not amenable for transport across the eucaryotic plasma membrane at considerable efficacy, irrespective of whether being modified at its carboxy-terminus with a GPI structure or not. However, the negatively charged amino acids at the surface of GPI$ß$-galactosidase can be (over-) compensated upon the introduction of positive charges by surface binding of NPs equipped with positively charged shell structures. Those GPI- $\beta$-galactosidase-NP complexes have been described to be efficiently taken up by eucaryotic cells $[127,128]$. The molecular mechanism involved in the rapid trafficking of GPI- $ß$-galactosidase from the extracellular medium via anchorage at the outer leaflet of the plasma membrane phospholipid bilayer to the cytosol is ill-defined. Apparently, it is based on a special type of clathrin-independent caveolin-mediated endocytosis which does not deliver its cargo to the endosomal/lysosomal degradation machineries.

The underlying trafficking pathway may be related to the recently described two-step transport of the GPI-proteins, Gcel and CD73, which are both engaged in cAMP metabolism, from extracellular microvesicles onto the surface of cytoplasmic lipid droplets of adipocytes [129]. It has been demonstrated that in course of incubation of microvesicles harbouring Gce1 and CD73 with rat adipocytes, the GPI-proteins consecutively associate with the plasma membrane and then with the lipid droplets in spontaneous and regulated fashion $[130,131]$. This ultimately leads to expression of the cAMP-degrading activities of Gcel and CD73 at the lipid droplet surface facing the cytoplasm [132,133]. Furthermore, GPI-proteins have been reported to be transported via transcytosis across rodent epithelial intestinal cells [100] and transferred between adipocytes of different size within the same adipose tissue depot via microvesicles [1334-135]. In analogy, the uptake of the GPI- $B$-galactosidase-NP complex by the eucaryotic cell seems to be mediated by the GPI anchor, in addition to the positively charged surface. The GPI anchor efficiently triggers the interaction with the surface of the cell as well as with the cytosolic lipid droplets, which are present in almost each cell type, albeit to a varying degree $[136,137]$. Upon arrival of the GPI-ß-galactosidase-NP complexes at the lipid droplet surface, the NPs will either remain bound to or become displaced from the $\beta$-galactosidase dependent on the absence or presence, respectively, of competing interaction partners. As those denatured, aggregated or misfolded passenger polypeptides may operate that are generated by ectopic high-level expression. In consequence, these may induce the upregulation of $ß$-galactosidase activity and of the corresponding light signal (Figure 10). Thus, the NPs employed will "smell and taste" the surface landscape of the $\beta$-galactosidase and the incorrectly folded/assembled passenger protein, but not of its intact native version, in comparative fashion. In consequence, the proportion of native to misfolded protein drugs in the host cells along upstream processing can be followed by incubation of portions of them with appropriate GPI-reporter enzyme-NP complexes.

\section{Automation}

This cellular NP-based test for assaying the molecular and structural integrity of protein drugs in host cells can be easily transferred from

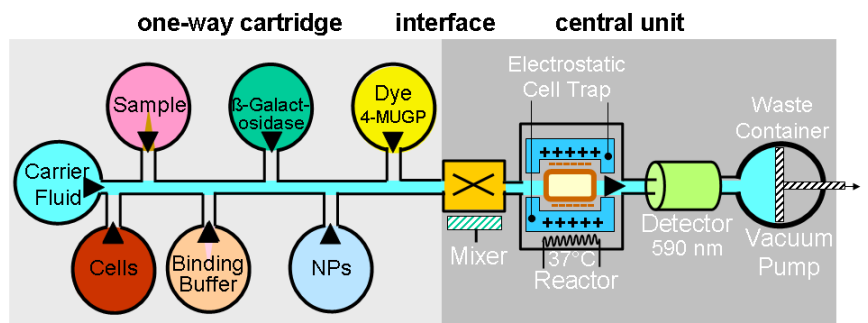

Figure 11: Automation of the NP-based cell chip. The individual reservoir chambers containing all the components required for the NP-based determination of the amount of misfolded protein drugs, including the host cells in suspension (see Figure 10), the carrier fluid, which mediates their regulated transfer via microfluidic channels, and the dye, 4-methylumbelliferyl- $\beta$-D-galactopyranoside (4-MUGP), are integrated into the one-way cartridge. The mixer, the reactor with the installed electrostatic cell trap, the photometric detector and the waste container are installed in a common central unit. The one-way cartridge and the central unit are connected via microfluidic channels and electrical interfaces. The reactor manages to trap and correctly position the host cells through electrostatic interactions between the cell surface and the trap wall. 
the microtiter plate format to the automated "lab-on-the-chip" format as described above for the "chip-on-the-chip" configuration. For this, the NP-based (GPI-) protein chips have to be adapted and supplemented with (an) additional reservoir chamber(s) for the cells to be assessed (Figure 11) [138]. Confining cells in micrometer-sized reservoir chambers close to their intrinsic volume enables the handling and analysis of a small number of cells with minimized dilution [139]. Initial approaches for "lab-on-the-chip" cell analysis have been performed with silicon microfilter chambers, microcolumn separation techniques and capillary electrophoresis $[140,141]$, including one- and two-dimensional resolving methods [141]. However, conventional capillary-based techniques lack the potential for high-throughput analysis of a few cells due to sophisticated cell-loading procedures. Microfluidic devices offer a versatile alternative to overcome this problem and enable the integration of the positioning and trapping of a limited number of cells on the micrometer scale. A typical workflow involves the transfer of a several-microliter sample of the cell suspension from an off-chip culture to the reservoir chamber of the microfluidic device [143]. A selection step for the cells of interest follows together with a navigation step in order to immobilise the cells at a certain trapping position in a downstream channel of the microfluidic device [144].

\section{Cell Trapping}

A variety of methods for the selection, navigation and trapping steps during the cell manipulation has been employed [144-146]. They commonly are based on mechanical, optical, magnetic field or electric field principles. For example, the mechanical trapping of cells using microfabricated filters or other physical barrier designs has proven successful, albeit, in general, it does not offer the versatility of other methods. Laser tweezers, magnetic fields and droplet-based microfluidics have been used to select, trap and move cells [147-150]. However, approaches involving the use of electrical fields remain the most popular, since they combine the ease of field generation and regulation with speed and flexibility. In particular, both electrophoresis and electroosmosis have been used extensively for sorting, transportation and navigation of cells in microchannels [151-154].

In case of the cellular NP-based (GPI-) protein chip, an electrostatic cell trap has been installed. It relies on multiple ionic interactions between the negatively charged surface of the yeast or eucaryotic cells, which are formed by the cell wall glucans and mannans or the plasma membrane phospholipids and transmembrane proteins, respectively, and the positively charged wall of the cell trap chamber (Figure 11). The positioning of the cells transported via the carrier fluid into the cell trap for the analysis and the release of the cells from the cell trap into the carrier fluid for delivery to the waste and initiation of the next cycle of measurement (with a distinct type of NPs or cell sample) after the analysis is under control of an electronic chip that regulates the electric field in the trap. However, it is known that a (pulsed) electric field applied onto a cell induces an extra transmembrane potential (TMP) across the cellular membrane, which can compromise its integrity $[155,156]$. The applied electric field may trigger the emergence of pores in the plasma membrane, which could increase in diameter and eventually become hydrophilic at a threshold TMP of 0.5-1 V. Below the threshold TMP, reversible electroporation occurs, in which pores are not generated at all or are formed but can reseal. The small distance between the electrodes installed in the chamber walls (Figure 11) allows the formation of electric field strengths $(<10 \mathrm{kV} \mathrm{cm}-1)$ sufficient for transient trapping and correct and stable positioning of the cells despite the low voltages applied. These are sufficiently low to avoid irreversible electroporation, mechanical breakdown of the plasma membrane, cell lysis and cell inactivation as well as electrolysis and problems associated with local gas generation and $\mathrm{pH}$ shifts.

An additional problem pertains to intrinsic cell-to-cell variability, which is particularly prominent in case of analysing a few cells, only [157]. Biochemical studies are routinely based on millions of cells for a single experiment and as a result record the average across this population. However, increasing evidence suggests that individual cells vary in their responses due to noise and by design. For example, protein levels fluctuate between different cells of the same population and stress signaling pathways are often designed to respond switch-like rather than with classical Michaelis-Menten type kinetics. However, a switch-like response of individual cells will be monitored as a graded response across a cell population. If stress conditions during fermentation increase the number of host cells accumulating misfolded proteins, they become indistinguishable at the population level from a genuinely graded response of individual cells [158]. It is of importance to discriminate these response types as the effects of stress during fermentation from cellular variability. In hypersensitive (switch-like) systems it is sufficient to induce the stress response above a threshold value in order to achieve a maximal amount of misfolded polypeptides, while an analogous system with a graded stress response will show increasing misfolding proportional to the increase in unfavourable fermentation conditions. Thus, it is of general importance to deconvolute cell population vs. few-cell responses [159]. It is assumed that in future applied physiology, biochemistry and cell biology will increasingly tackle this problem for microengineering of "lab-on-thechips" as well as for chip-based life cell analysis $[160,161]$.

\section{Software-Based Bioanalytics}

The measurement of product parameters critical for the quantity and quality of the protein drug, such as amount, identity, structure, function, non-immunogenicity and non-toxicity, in the course of process validation, risk analysis and process control is admittedly accompanied by considerable technical difficulties and expenditure. Therefore, many attempts have been initiated to predict product parameters from relevant process parameters that are seemingly more easily to follow, such as glucose, oxygen, $\mathrm{pH}$ and temperature for the fermentation process. For this, a specific software called the "softsensor" was developed that is fuelled with data obtained from the simple online-measurement of the process parameters at the efflux channel of the bioreactor (Figure 12). As an advantage, there is no need for additional sample collection and analytical equipment for the generation of "softsensor"-specific experimental data. Instead the "softsensor" relies on model calculations and algorithms which are driven by "historical" experimental data. These have been derived from previous systematic variation of the corresponding process parameters, such as for the fermentation step. The relevant product parameters, which are directly or indirectly dependent on the process parameters, will then be calculated by transformation of these process parameters upon their online measurement. These "actual" values are then forwarded to the regulatory control unit for comparison with the corresponding "ideal" values. In case of a calculated difference, the control unit, which is connected to electric valves for the regulation of the supply with medium, oxygen, buffer etc., will induce increases or decreases of the corresponding influxes for compensation of eventual deficiencies or excesses, respectively.

In combining the most critical parameters for a specific process, such as fermentation, this configuration is designed for the automated 


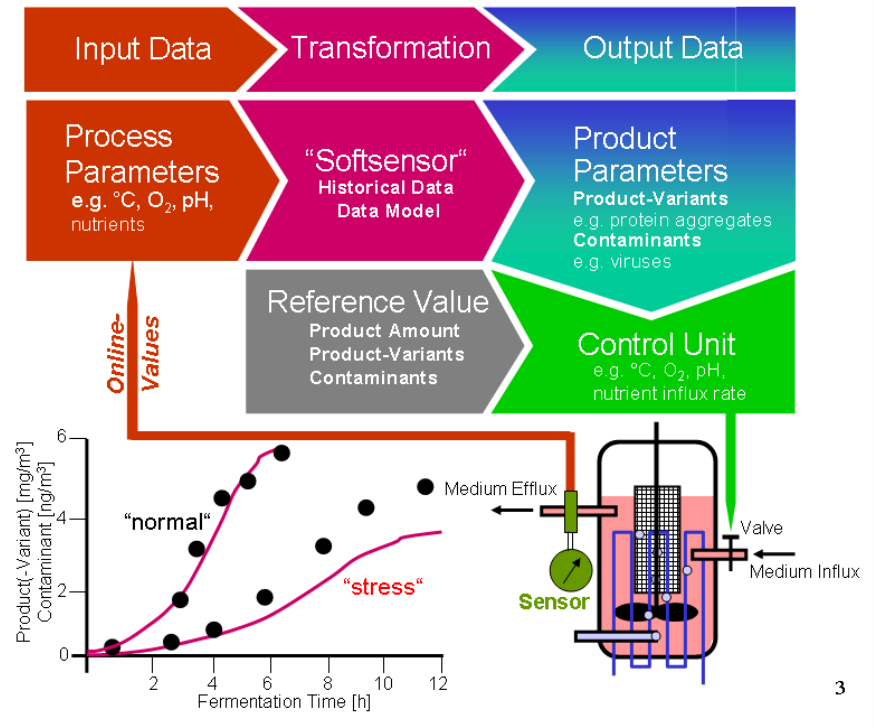

Figure 12: Software-based process bioanalytics. Output data on product parameters are derived from the input data on process parameters that are actually measured online and then transformed on the basis of historical data and a data model by the "softsensor". The process, e.g. fermentation, will be regulated by the control unit which regulates the influx of medium, oxygen and buffer as well as the operation of heating and cooling devices in comparison to reference values for the corresponding product parameter. The diagram shows the change of product parameters along the fermentation period under normal and "stress conditions". Black circles, measured data; pink line, data calculated by the "softsensor".

process control on the basis of estimated and predicted product parameters. In fact, under standard conditions the "softsensor" will predict the critical product parameters, such as amount of the authentic protein drug or the emergence of product variants, e.g. modified protein drug, from the relevant process parameters, such as glucose or oxygen concentration in the fermentation broth, with remarkable accuracy. This is concluded from the almost perfect match of the calculated and the experimentally determined values (Figure 12). Thus, standard conditions during "regular" operations are compatible with the capability of the "softsensor" to delineate the causal relationship between process and product parameters. However, "non-standard" conditions during "irregular" operations that may occur rarely, but can never be excluded, are not and per se can not be predicted in the data model that forms the basis of the "softsensor". In consequence, they can not be calculated and estimated by the "softsensor".

Taken together, there are considerable advantages for the application of the "softsensor" in process analytics that encompass (i) the simple continuous real-time observation of all critical steps in upstream and downstream processing, (ii) the use of already available online-data rather than expensive instrumentation, (iii) the estimation of the "true" product parameters with reasonable accuracy as long as the corresponding process operates within the "normal" range, and (iv) the valuable supplementation of modern and intelligent process control and automation. Certainly, the "softsensor" will be installed for future process analytics on a routine basis (Figure 12). However, the "softsensor" does not replace the need for the generation of experimental data regarding relevant product parameters, such as the product amount, product variants and contaminants, and this is true for both seemingly normally and, in particular, obviously irregularly operating processes. Thus, the "softsensor" will not substitute for the "hardware analytics" that relies on bioanalytical tests and assays including the appropriate instrumentations and data analyses.

\section{Conclusions and Perspectives}

The following general consequences have to be drawn for the stateof-the-art process analytics in biopharmaceutical production: (i) Largescale production of protein drugs is subject to errors and heterogeneity. (ii) Analysis of the production process relies on the deep understanding of the relationship between the individual production steps (under normal and irregular conditions) and the authentic product, product variants and contaminants. (iii) "Software-based" analytics will supplement, but not substitute for "hardware-based" analytics. (iv) Test qualification and validation critically depend on the production steps, product variants and contaminants to be followed. (v) Combinations of several tests evaluating distinct product parameters, such as identity, structure and function, are preferred vs. a single test system. (vi) Specific adaptation of the test (combination) for the corresponding production step and relevant parameter is usually required. (vii) For any given production step and parameter the tests are not "ideal" and "fixed" in most cases, but rather represent acceptable compromises at the time point of implementation. They have to be improved according to current state-of-the-art both with regard to the regulatory and technological progress [162-171]. Examples for recent breakthroughs in the parallel multi-parameter process analytics represent cell-free and cell-based protein chips and biosensors relying on GPI-proteins as capturing/immobilising probes and NPs as detection probes which can be integrated into chip-on-the-chip and lab-on-the-chip formats for full automatic routine handling.

This kind of relativism reflected in "non-ideal" and "non-fixed" tests apparently underlies each bioanalytical procedure, in general, and test qualification, in particular. The relativism of process bioanalytics displays some interesting parallels with other analytical processes, for instance the interpretation of music pieces. Starting with the compository material, adequate musical instruments and knowledge about the process of its composing, including eventually the biography of the composer, are prerequisites. Nevertheless, there will be enough space left for creativity and inspiration for the musician as well as for the bioanalyst. This apparent relative freedom, by no means to mix up with randomness, in the interpretation of bioanalytical data represents the most interesting aspect in the field of process analytics.

\section{References}

1. Kelley B, Greg B, Lee A (2009) Downstream processing of monoclonal antibodies: current practices and future opportunities. (Gottschalk U, edn), In Process Scale Purification of Antibodies. John Wiley \& Sons.

2. Low D, O'Leary R, Pujar NS (2007) Future of antibody purification. J Chromatogr B 848: 48-63.

3. Sommerfeld S, Strube J (2005) Challenges in biotechnology production generic processes and process optimization for monoclonal antibodies. Chem Eng Process 44: 1123-1137.

4. Nfor BK, Ahamed T, van Dedem GW, van der Wielen LA, van de Sandt EJ et al. (2008) Design strategies for integrated protein purification processes: challenges, progress and outlook. J Chem Technol Biotechnol 83: 124-132.

5. Asenjo JA, Andrews BA (2004) Is there a rational method to purify proteins? From expert systems to proteomics. J Mol Recognit 17: 236-247.

6. Bensch M, Schulze Wierling P, von Lieres E, Hubbuch J (2005) High throughput screening of chromatographic phases for rapid process development. Chem Eng Technol 28: 1274-1284.

7. Rege K, Pepsin M, Falcon B, Steele L, Heng M (2006) High-throughput process development for recombinant protein purification. Biotechnol Bioeng 93: 618630 . 
8. Wiendahl M, Schulze Wierling P, Nielsen J, Fomsgaard Christensen D, Krarup $\mathrm{J}$, et al.(2008) High throughput screening for the design and optimization of chromatographic processes - miniaturization, automation and parallelization of breakthrough and elution studies. Chem Eng Technol 31: 893-903.

9. Gosling I (2005) Process simulation and modeling for industrial bioprocessing: tools and techniques. Indust Biotechnol 1: 106-109.

10. Lu Y, Clarkson A, Titchener-Hooker N, Pantelides C, Bogle D (1994) Simulation as a tool in process designing and management for production of intracellular enzymes. Chem Eng Res Des 72: 371-375.

11. Petrides DP (1994) BioPro Designer: an advanced computing environment for modeling and design of integrated biochemical processes. Comp Chem Eng 18: S621-S625.

12. Hodge G (2004) Investing in process development. Bioprocess J 31-35.

13. FDA (2004) Guidance for industry PAT - A framework for innovative pharmaceutical development, manufacturing and quality assurance, FDA.

14. FDA (2009) International committee on harmonization, Q8: Pharmaceutical Development, FDA.

15. Schuppenhauer M (2003) BioCentury A5.

16. Clementschitsch F, Kern J, Pötschacher F, Bayer K (2005) Sensor combination and chemometric modeling for improved process monitoring in recombinant $E$. coli fed-batch cultivations. J Biotechnol 120: 183-196.

17. Baker KN, Rendall MH, Patel A, Boyd P, Hoare M, et al. (2002) Rapid monitoring of recombinant protein products: a comparison of current technologies. Trends Biotechnol 20: 149-156.

18. Peuker T, Riedel M, Kaiser C, Ellert A, Lenz K, et al. (2004) At-line determination of glucose, ammonia, and acetate in high cell density cultivations of Escherichia coli. Eng Life Sci 4: 138-143.

19. Forrer K, Hammer S, Helk B (2004) Chip-based gel electrophoresis method for the quantification of half-antibody species in $\lg G 4$ and their by- and degradation products. Anal Biochem 334: 81-88.

20. Vasilyeva E, Woodard J, Taylor FR, Kretschmer M, Fajardo H, et al. (2004) Development of a chip-based capillary gel electrophoresis method for quantification of a half-antibody in immunoglobulin $\mathrm{G}_{4}$ samples. Electrophoresis 25: 3890-3896

21. Müllner S, Karbe-Thönges B, Tripier D (1993) Charge heterogeneity of insulin fusion proteins expressed in Escherichia coli is not due to proteolytic degradation. Anal Biochem 210: 366-373.

22. Nettleton EJ, Tito P, Sunde M, Bouchard M, Dobson CM, et al. (2000) Characterization of the oligomeric states of insulin in self-assembly and amyloid fibril formation by mass spectrometry. Biophys J 79: 1053-1065.

23. Staack RF, Stracke JO, Stubenrauch K, Vogel R, Schleypen J, et al. (2011) Quality requirements for critical assay reagents used in bioanalysis of therapeutic proteins: what bioanalysts should know about their reagents. Bioanalysis 3: $523-534$

24. Kuster B, Mann M (1998) Identifying proteins and post-translational modifications by mass spectrometry. Curr Opin Struct Biol 8: 393-400

25. Sluzky V, Tamada JA, Klibaonov AM, Langer R (1991) Kinetics of insulin aggregation in aqueous solutions upon agitation in the presence of hydrophobic surfaces. Proc Natl Acad Sci USA 88: 9377-9381.

26. CBER (Center for Biologics Evaluation and Research)(1994) Points to consider in the manufacturing and testing of monoclonal antibody products for human use. Rockville: Food and Drug Administration.

27. Eaton LC (1995) Host cell contaminant protein assay development for recombinant biopharmaceuticals. J Chromatogr A 705: 105-114.

28. Shadle PJ, McAllister PR, Smith TM, Lubiniecki AS (1995) Viral validation strategy for recombinant products derived from established animal cell lines. Cytotechnol 18: 21-25

29. Entzeroth M (2003) Emerging trends in high-throughput screening. Curr Opin Pharmacol 3: 522-529.

30. CPMP Biotechnology Working Party (1996) Note for guidance on virus validation studies: the design, contribution and interpretation of studies validation, the inactivation and removal of viruses. London: The European Agency for the Evaluation of Medical Products, Canary Wharf.
31. Poiley JA, Bierley ST, Hillesund T, Nelson RE, Monticello TM, et al. (1994) Methods for estimating retroviral burden. Pharmaceutic Technol 5: 32-35.

32. Lubiniecki AS, Wiebe ME, Builder SE (1990) Process validation for cell culturederived pharmaceutical proteins. Bioprocess Technol 10: 515-541.

33. CDER/CBER/CDRH/CVR-FDA (1987) Guidelines on validation of the limulus amebocyte lysate test as an end-product endotoxin test for human and animal parenteral drugs, biological products, and medical devices.

34. ICH, Q5A (1998) Guidance for industry: viral safety evaluation of biotechnology products derived from cell lines of human or animal origin.

35. Werz W, Werner RG (1998) Recombinant tissue plasminogen activator (rt-PA) in fibrinolytic therapy. J Biotechnol 61: 157-158.

36. Eaton LC (1989) Quantification of putative glycoprotein X in bioengineered pseudorabies vaccine virus culture medium by ELISA. J Immunol Methods 118: $125-128$.

37. Hammerl P, Hartl A, Thalhamer J (1993) Particulate nitrocellulose as a solid phase for protein immobilization in immuno-affinity chromatography. J Immuno Methods 165: 59-66.

38. Hammerl P, Hartl A, Thalhamer J (1993) Improvement of antisera raised against complex antigen mixtures by the use of heterologous sources of antigen for immunization. J Immunol Methods 160: 155-161.

39. Flatman S, Alam I, Gerard J, Mussa N (2007) Process analytics for purification of monoclonal antibodies. J Chromatogr B 848: 79-87.

40. Nfor BK, Verhaert PDEM, van der Wielen LAM, Hubbuch J, Ottens M (2009) Rational and systematic protein purification process development: the next generation. Trends Biotechnol 27: 673-679.

41. Graumann K, Premstaller A (2006) Manufacturing of recombinant therapeutic proteins in microbial systems. Biotechnol J 1: 164-186.

42. Thomas A, Thevis M, Delahaut P, Bosseloir A, Schänzer W (2007) Mass spectrometric identification of degradation products of insulin and its long acting analogues in human urine for doping control purposes. Anal Chem 79: 2518-2524.

43. Fabris D, Fenselau C (1999) Characterization of allosteric insulin hexamers by electrospray ionization mass spectrometry. Anal Chem 71: 384-387.

44. Kuster B, Mann M (1998) Identifying proteins and post-translational modifications by mass spectrometry. Curr Opin Struct Biol 8: 393-400.

45. Goldman J, Carpenter FH (1974) Zinc binding, circular dichroism, and equilibrium sedimentation studies on insulin (bovine) and several of its derivatives. Biochemistry 13: 4566-4574.

46. Vecchio G, Bossi A, Pasta P, Carrea G (1996) Fourier-transform infrared conformational study of bovine insulin in surfactant solutions. Int J Pep Prot Res 48: 113-117.

47. Wei J, Lin YZ, Zhou JM, Tsou CL (1991) FT-IR studies of secondary structures of bovine insulin and its derivatives. Biochem Biophys Acta 1080: 29-33.

48. Mercolini L, Musenga A, Saladini B, Bigucci F, Luppi B, Zecchi V, Raggi MA (2008) Determination of insulin in innovative formulations by means of LC coupled to fluorescence detection. J Pharmaceut Biomed Analy 48: 1303-1309.

49. Hua Q, Weiss MA (1991) Comparative 2D-NMR studies of human insulin and des-pentapeptide insulin-sequential resonance assignment and implications for protein dynamics and receptor recognition. Biochemistry 30: 5505-5515.

50. Sommerfeld M, Müller G, Tschank G, Seipke G, Habermann P, et al. (2010) In vitro metabolic and mitogenic signaling of insulin glargine and its metabolites. PLoS One 5: e9540.

51. Müller G, Ertl J, Gerl M, Preibisch G (1997) Leptin impairs metabolic actions of insulin in isolated rat adipocytes. J Biol Chem 272: 10585-10593.

52. Müller G, Herling A, Sandow J (2008) Antidiabetic activity in drug discovery and evaluation-Pharmacological assays .(Vogel HG Edn) Berlin, Heidelberg. New York.

53. Müller G, Jordan H, Petry S, Wetekam E-M, Schindler P (1997) Analysis of lipid metabolism in adipocytes using fluorescent fatty acids. I. Insulin stimulation of lipogenesis. Biochim Biophys Acta 1347: 23-39.

54. IABs international meeting (2001) Immunogenicity testing. Immunogenicity of therapeutic biological products 
Citation: Müller G (2012) (Glycosylphosphatidylinositol-Based) Protein Chips and Biosensors for Biopharmaceutical Process Analytics. J Bioprocess Biotechniq 2:115 doi: 10.4172/2155-9821.1000115

Page 19 of 21

55. CDER/CBER/CDRH/CVR-FDA (1997) Guidelines on validation of the limulus amebocyte lysate test as an end-product endotoxin test for human and animal parenteral drugs, biological products, and medical devices.

56. Flatman S, Alam I, Gerard J, Mussa N (2010) Process analytics for purification of monoclonal antibodies. J Chromatogr B Analyte Technol Biomed Life Sci 848: 79-87.

57. Lottspeich F (2009) Introduction to proteomics. Methods Mol Biol 564: 3-10.

58. Chen R, Snyder M (2010) Yeast proteomics and protein microassays. J Proteom 73: 2147-2157.

59. Lynch M, Mosher C, Huff J, Nettikadan S, Johnson J, Henderson E (2004) Functional protein nanoarrays for biomarker profiling. Proteomics 4: 1695-1702.

60. Lin JC-H (2010) Protein microarrays for cancer diagnostics and therapy. Med Princ Pract 19: 247-254.

61. Malinowsky K, Wolff C, Ergin B, Berg D, Becker KF (2010) Deciphering signaling pathways in clinical tissues for personalized medicine using protein microarrays. J Cell Physiol 225: 364-370.

62. Mueller C, Liotta LA, Espina V (2010) Reverse phase protein microarrays advance to use in clinical trials. Mol Oncol 4: 461-481.

63. Yang L, Guo S, Li Y, Zhou S, Tao S (2011) Protein microarrays for systems biology. Acta Biochim Biophys Sin 43: 161-171.

64. Merbl Y, Kirschner MW (2011) Protein microarrays for genome-wide posttranslational modification analysis. WIREs Syst Biol Med 3: 347-356

65. Park J, Kurosawa S, Takai M, Ishihara K (2007) Antibody immobilization to phospholipid polymer layer on gold substrate of quartz crystal microbalance immunosensor. Colloid Surf B Biointerf 55: 164-172.

66. Hu S, Xie Z, Qian J, Blackshaw S, Zhu H (2011) Functional protein microarray technology. WIREs Syst Biol Med 3: 255-268.

67. Templin MF, Stoll D, Schrenk M, Traub PC, Vöhringer CF, et al. (2002) Protein microarray technology. Trends Biotechnol 20: 160-166.

68. Zhu H, Bilgin M, Bangham R, Hall D, Casamayor A, Bertone P, Lan D (2001) Global analysis of protein activities using proteome chips. Science 293: 2101 2105

69. MacBeath G, Schreiber SL (2000) Printing proteins as microarrays for hightroughput function determination. Science 289: 1760-1763.

70. Delehanty JB, Ligler FS (2003) Method for printing functional protein microarrays. Biotechniques 34: 380-385.

71. Delehanty JB (2004) Printing functional protein microarrays using piezoelectric capillaries. Methods Mol Biol 264: 135-143.

72. Jones VW, Kenseth JR, Porter MD, Mosher CL, Henderson E (1998) Microminiaturized immunoassays using atomic force microscopy and compositionally patterned antigen arrays. Anal Chem 70: 1233-1241.

73. Kusnezow W, Jacob A, Walijew A, Diehl F, Hoheisel JD (2003) Antibody microarrays: an evaluation of production parameters. Proteomics 3: 254-264.

74. Kramer A, Feilner T, Possling A, Radchuk V, Weschke W, et al. (2004) Identification of barley CK2alpha targets by using the protein microarray technology. Phytochemistry 65: 1777-1784.

75. Stillman BA, Tonkinson JL (2000) FAST slides: a novel surface for microarrays. Biotechniques 29: 630-635.

76. Angenendt P, Glokler J, Murphy D, Lehrach H, Cahill DJ (2002) Toward optimized antibody microarrays. a comparison of current microarray support materials. Anal Biochem 309: 253-260.

77. Charles PT, Goldmn ER, Rangasammy JG, Schauer CL, Chen MS, et al. (2004) Fabrication and characterization of 3D hydrogel microarrays to measure antigenicity and antibody functionality for biosensor applications. Biosens Bioelectron 20: 753-764.

78. Feilner T, Hultschig C, Lee J, Meyer S, Immink RG, et al. (2005) High throughput identification of potential Arabidopsis mitogen-activated protein kinase substrates. Mol Cell Proteomics 4: 1558-1568.

79. Chen CS, Korobkova E, Chen H, Zhu J, Jian X, et al. (2008) A proteome chip approach reveals new DNA damage recognition activities in Escherichia coli. Nat Methods 5: 69-74.
80. Alhamdani MS, Schroder C Hoheisel JD (2010) Analysis conditions for proteomic profiling of mammalian tissue and cell extracts with antibody microarrays. Proteomics 10: 3203-3207.

81. Gulmann C, Sheehan KM, Conroy RM, Wulfkuhle JD, Espina V, et al. (2009) Quantitative cell signalling analysis reveals down-regulation of MAPK pathway activation in colorectal cancer. J Pathol 218: 514-519.

82. Jones RB, Gordus A, Krall JA, MacBeath GA (2006) A quantitative protein interaction network for the ErbB receptors using protein microarrays. Nature 439: $168-174$

83. Hsu KL, Mahal LK (2006) A lectin microarray approach for the rapid analysis of bacterial glycans. Nat Protoc 1: 543-549.

84. Tao SC, Li Y, Zhou J, Qian J, Schnaar RL, et al. (2008) Lectin microarrays identify cell-specific and functionally significant cell surface glycan markers. Glycobiology 18: 761-769.

85. Lueking A, Horn M, Eickhoff $H$, Bussow K, Lehrach $H$, et al. (1999) Protein microarrays for gene expression and antibody screening. Anal Biochem 270 : 103-111.

86. SC, Chen CS, Zhu H (2007) Applications of protein microarray technology Comb Chem High Throughput Screen 10: 706-718.

87. Hamelinck D, Zhou H, Li L, Verweij C, Dillon D, et al. (2005) Optimized normalization for antibody microarrays and application to serum protein profiling. Mol Cell Proteomics 4: 773-784.

88. Wingren C, Borrebaeck CA (2008) Antibody microarray analysis of directly labelled complex proteosomes. Curr Opin Biotechnol 19: 55-61.

89. Wingren C, Ingvarsson J, Dexlin L, Szul D, Borrebaeck CA (2007) Design of recombinant antibody microarrays for complex proteome analysis: choice of sample labeling-tag and solid support. Proteomics 7: 3055-3065.

90. Chen CS, Zhu H (2006) Protein microarrays. Biotechniques 40: 423-425.

91. Müller G , Wetekam E-M, Jung C, Bandlow W (1994) Membrane association of lipoprotein lipase and a cAMP-binding ectoprotein in rat adipocytes. Biochemistry 33: 12149-12159.

92. Nosjean O, Briolay A, Roux B (1997) Mammalian GPI proteins: sorting membrane residence and functions. Biochim Biophys Acta 1331: 153-186.

93. Ikezawa H (2002) Glycosylphosphatidylinositol (GPI)-anchored proteins. Biol Pharm Bull 25: 409-417.

94. Caras IW, Weddell GN (1989) Signal peptide for protein secretion directing glycophospholipid membrane anchor attachment. Science 243: 1196-1198.

95. Orlean P, Menon AK (2007) Theamtic review series: lipid post-translational modifications. GPI anchoring of protein in yeast and mammalian cells, or: How we learned to stop worrying and love glycophospholipids. J Lipid Res 48: 9931011.

96. Pittet A, Conzelmann A (2007) Biosynthesis and function of GPI proteins in the yeast Saccharomyces cerevisiae. Biochim Biophys Acta 1771: 405-420.

97. Tiede A, Bastisch I, Schubert J, Orlean P, Schmidt RE (1999) Biosynthesis of glycosylphosphatidylinositols in mammals and unicellular microbes. Biol Chem 380: 503-523.

98. Kinoshita T, Fujita M, Maeda Y (2008) Biosynthesis, remodelling and functions of mammalian GPI-anchored proteins: Recent progress. J Biochem 144: 287 294

99. Varma R, Mayor S (1998) GPI-anchored proteins are organized in submicron domains at the cell surface. Nature 394: 798-801.

100. G (2011) Novel applications for glycosylphosphatidylinositol-anchored proteins in pharmaceutical and industrial biotechnology. Mol Membr Biol 28: 187-205.

101. Nosjean O, Roux B (1999) Ectoplasmic insertion of a glycosylphosphatidylinositol-anchored protein in glycosphingolipid- and cholesterol-containing phosphatidylcholine vesicles. Eur J Biochem 263: 865-870.

102. Nosjean O, Roux B (2003) Anchoring of glycosylphosphatidylinositol-proteins to liposomes. Methods Enzymol 372: 216-232.

103. Sesana S, Re F, Bulbarelli A, Salerno D, Cazzaniga E, et al. (2008) Membrane features and activity of GPI-anchored enzymes: alkaline phosphatase reconstituted in model membranes. Biochemistry 47: 5433-5440.

104. llangumaran S, Robinson PJ, Hoessli DC (1996) Transfer of exogenous 
Citation: Müller G (2012) (Glycosylphosphatidylinositol-Based) Protein Chips and Biosensors for Biopharmaceutical Process Analytics. J Bioprocess Biotechniq 2:115 doi: 10.4172/2155-9821.1000115

Page 20 of 21

glycosylinositol (GPI)-linked molecules to plasma membranes. Trends Cell Biol 6: 163-167

105. Miranda OR, Creran B, Rotello VM (2010) Array-based sensing nanoparticles: 'Chemical noses' for sensing biomolecules and cell surfaces. Curr Opin Chem Biol 14: 728-736.

106. Miranda OR, Chen HT, Chang-Cheng Y, Mortenson DE, Yang XC, et al. (2010) Enzyme-amplified array sensing of proteins in solution and in biofluids. J Am Chem Soc 132: 5285-5289.

107. Picollet-D'hahan N (2011) Live cell analysis: When electric detection interfaces microfluidics. J Biochip Tissue chip S1-001.

108. Mallick P, Kuster B (2010) Proteomics: a pragmatic perspective Nat Biotechnol 28: 695-709.

109. Anslyn EV, Rotello VM (2010) Chemosensory models: approaches and applications of differential sensing. Curr Opin Chem Biol 14: 683-684.

110. Baldini L, Wilson AJ, Hong J, Hamilton AD (2004) Pattern-based detection of different proteins using an array of fluorescent protein surface receptors. J Am Chem Soc 126: 5656-5657.

111. Sannomiya T, Vörös J (2011) Single plasmonic nanoparticles for biosensing Trends Biotechnol 29: 343-351.

112. Lei J, Ju H (2010) Nanotubes in biosensing. Nanomed Nanobiotechnol 2: 496509.

113. Nambiar S, Yeow JT (2011) Conductive polymer-based sensors for biomedical applications. Biosens Bioelectron 26: 1825-1832.

114. Ray S, Chandra H, Srivastava S (2010) Nanotechniques in proteomics: Current status, promises and challenges. Biosens Bioelectron 25: 2389-2401.

115. M, Rana S, Akpinar H, Miranda OR, Arvizo RR, et al. (2009) Sensing of proteins in human serum using nanoparticle-green fluorescent protein conjugates. Nat Chem 1: 461-465.

116. Rana SS, Yeh YC, Rotello VM (2010) Engineering the nanoparticle-protein interface: applications and possibilities. Curr Opin Chem Biol 14: 828-834

117. Wright AT, Griffin MJ, Zhong Z, McCleskey SC, Anslyn EV, et al. (2005) Differential receptors create patterns that distinguish various proteins. Angew Chem Int Ed Engl 44: 6375-6378.

118. Müller G (2011) Glycosylphosphatidylinositol-Anchored Protein Chips for Patient-Tailored Multi-Parameter Proteomics. J Biochip Tissue chip S3: 001.

119. Fuchs SM, Raines RT (2004) Pathway for polyarginine entry into mammalian cell. Biochemistry 43: 2438-2444.

120. Futami J, Yamada H (2008) Design of cytotoxic ribonucleases by cationization to enhance intracellular protein delivery. Curr Pharm Biotechnol 9: 180-184.

121. Turcotte RF, Lavis LD, Raines RT (2009) Onconase cytotoxicity relies on the distribution of its positive charge. FEBS J 276: 3846-3857.

122. Futami J, Maeda T, Kitazoe M, Nukui E, Tada H, et al. (2001) Preparation of potent cytotoxic ribonucleases by cationization. Enhanced cellular uptake and decreased interaction with ribonuclease inhibitor by chemical modification of carboxyl groups. Biochemistry 26: 7518-7524.

123. Gosh P, Yang X, Arvizo R, Zhu ZJ, Agasti SS, et al. (2010) Intracellular delivery of a membrane-impermeable enzyme in active using functionalized gold nanoparticles. J Am Chem Soc 132: 2642-2645.

124. Kim CK, Ghosh P, Rotello VM (2009) Multimodal drug delivery using gold nanoparticles. Nanoscale 1: 61-67.

125. Amand HL, Fant K, Norden B, Esbjorner EK (2008) Stimulated endocytosis in penetratin uptake: Effect of arginine and lysine. Biochem Biophys Res Commun 371: 621-625.

126. Fuchs SM, Raines RT (2007) Arginine grafting to endow cell permeability. ACS Chem Biol 2: 167-170.

127.Müller G, Over S, Wied S, Frick W (2008) Association of (c)AMP-degrading glycosylphosphatiylinositol-anchored proteins with lipid droplets is induced by palmitate, $\mathrm{H} 2 \mathrm{O} 2$ and the sulfonylurea drug, glimepiride, in rat adipocytes. Biochemistry 47: 1274-1287.

128. Müller G, Jung C, Wied S, Biemer-Daub G, Frick W (2010) Transfer of the glycosylphosphatidylinositol-anchored 5'-nucleotidase CD73 from adiposomes into rat adipocytes stimulates lipid synthesis. Brit J Pharmacol 160: 878-891.
129. Müller G, Jung C, Wied S (2008) Translocation of glycosylphosphatidylinositolanchored proteins from plasma membrane microdomains to lipid droplets in rat adipocytes is induced by palmitate, $\mathrm{H} 2 \mathrm{O} 2$ and the sulfonylurea drug, glimepiride. Mol Pharmacol 73: 1513-1529.

130. Müller G, Wied S, Jung C, Over S (2008) Hydrogen peroxide-induced translocation of glycolipid-anchored (c)AMP-hydrolases to lipid droplets mediates inhibition of lipolysis in rat adipocytes. Brit J Pharmacol 154: 901 913.

131. Müller G, Jung C, Straub J, Wied S, Kramer W (2009) Induced release of membrane vesicles from rat adipocytes containing glycosylphosphatidylinositolanchored microdomain and lipid droplet signalling proteins. Cell Signal 21: 324-338.

132. Müller G, Schneider M, Biemer-Daub G, Wied S (2011) Microvesicles released from rat adipocytes and harboring glycosylphosphatidylinositol-anchored proteins transfer RNA stimulating lipid synthesis. Cell Signal 23: 1207-1223.

133. Müller G (2011) Take-over - Multiple mechanisms of inter-adipocyte communication. J Mol Cell Biol 3: 81-90.

134. Müller G (2010) Oral protein therapy for the future? Transport of glycolipidmodified therapeutic proteins:vision or fiction? Pharmacology 86: 92-116.

135. Müller G (2011) Oral delivery of protein drugs - Driver of personalized medicine ? Curr Issues Mol Biol 13: 13-24.

136. Ducharme NA, Bickel PE (2008) Lipid droplets in lipogenesis and lipolysis. Endocrinology 149: 942-949.

137. Fuimoto T, Ohsaki Y, Cheng J, Suzuki M, Shinohara Y (2008) Lipid droplets: a classic organelle with new outfits. Histochem Cell Biol 130: 263-279.

138. Andersson $H$, van der Berg A (2003) Microfluidic devices for cellomics: a review. Sens Actuators B 92: 315-325.

139. Andersson $\mathrm{H}$, van den Berg A (2004) Microtechnologies and nanotechnologies for single-cell analysis. Curr Opin Biotechnol 15: 44-49.

140. Preckel T, Luedke G, Chan SDH, Wang B, Dubrow R, Buhlmann C (2002) Detection of cellular parameters using a microfluidic chip-based system. J Assoc Lab Autom 7: 85-89.

141.Lundqvist JA, Sahlin F, Aberg MA, Strömberg A, Eriksson PS, et al. (1998) Altering the biochemical state of individual cultured cells and organelles with ultramicroelectrodes. Proc Natl Acad Sci USA 95: 10356-10360.

142. Wallingford RA, Ewing AG (1988) Capillary zone electrophoresis with electrochemical detection in 12.7 microns diameter columns. Anal Chem 60: 1972-1975.

143. Toriello NM, Douglas ES, Mathies RA (2005) Microfluidic device for electric field-driven single-cell capture and activation. Anal Chem 77: 6935-6941.

144. Wheeler AR, Throndset WR, Whelan RJ, Leach AM, Zare RN, et al. (2003) Microfluidic device for single-cell analysis. Anal Chem 75: 3581-3586.

145. Li PCH, Harrison DJ (1997) Transport, manipulation and reaction of biological cells on-chip using electrokinetic effects. Anal Chem 69: 1564-1568.

146. Price AK, Culbertson CT (2007) Chemical analysis of single mammalian cells with microfluidics. Anal Chem 79: 2614-2621.

147. Kennedy RT, Oates MD, Cooper BR, Nickerson B, Jorgenson JW (1989) Microcolumn separations and the analysis of single cells. Science 246: 57-63.

148. Hellmich W, Pelargus C, Leffhalm K, Ros A, Anselmetti D (2005) Single cell manipulation, analytics, and label-free protein detection in microfluidic devices for systems nanobiology. Electrophoresis 26: 3689-3696.

149.Buhlmann C, Preckel T, Chan S, Luedke G, Valer M (2003) A new tool for routine testing of cellular protein expression: Integration of cell staining and analysis of protein expression on a microfluidic chip-based system. J Biomol Tech 14: 119-127.

150. Cai X, Klauke N, Glidle A, Cobbold P, Smith G, et al. (2002) Ultra-low-volume real-time measurement of lactate from the single heart cell using microsystems technology. Anal Chem 74: 908-914.

151. Carlson R, Gabel C, Chan S, Austin R (1997) Self-sorting of white blood cells in a lattice. Phys Rev Lett 79: 2149-2152.

152. Chao T-C, Ros A (2008) Microfluidic single-cell analysis of intracellular compounds. J R Soc Interface 5: S139-S150. 
Citation: Müller G (2012) (Glycosylphosphatidylinositol-Based) Protein Chips and Biosensors for Biopharmaceutical Process Analytics. J Bioprocess Biotechniq 2:115 doi: 10.4172/2155-9821.1000115

153. Sedgwick H, Caron F, Monaghan PB, Kolch W, Cooper JM (2008) Lab-on-achip technologies for proteomic analysis from isolated cells. J R Soc Interface 5: S123-S130.

154. Wong PK, Wang TH, Deval JH, Ho CM (2004) Electrokinetics in micro devices for biotechnological applications. IEEE/ASME Trans Mechatron 9: 366-376.

155. Yi C, Zhang Q, Li CW, Yang J, Zhao J, Yang M (2006) Optical and electrochemical detection techniques for cell-based microfluidic systems. Anal Bioanal Chem 384: 1259-1268.

156. Yi C, Li C-W, Ji S, Yang M (2006) Microfluidics technology for manipulation and analysis of biological cells. Anal Chim Acta 560: 1-23.

157. Sigal A, Milo R, Cohen A, Geva-Zatorsky N, Klein Y,et al. (2006) Variability and memory of protein levels in human cells. Nature 444: 643-646.

158. Ferrel JE, Xiong W (2001) Bistability in cell signaling: how to make continuous processes discontinuous, and reversible processes irreversible. Chaos 11: 227-236.

159. Wilding P, Kricka LJ, Cheng J, Hvichia G, Shoffner MA, et al. (1998) Integrated cell isolation and polymerase chain reaction analysis using silicon microfilter chambers. Anal Biochem 257: 95-100.

160. Di Carlo D, Lee LP (2006) Dynamic single-cell analysis for quantitative biology. Anal Chem 78: 7918-7925
161. Picollet-D'hahan N (2011) Live cell analysis: When electric detection interfaces microfluidics. J Biochip Tissue chip S1:001

162. ICH (1998) Q5A Guidance for industry: viral safety evaluation of biotechnology products derived from cell lines of human or animal origin.

163. FDA (1988) Guideline for submitting documentation for the stability of human drugs and biologics.

164.ICH (1996) Q5C Guideline for industry: quality of biotechnological products: stability testing of biotechnological/biological products.

165. ICH (2002) Q1A (R1) Stability testing of new drug substances and products.

166. ICH (2002) Q1E Evaluation of stability data

167.US Pharmacopeia (2003) USP 26-NF 21

168. European Pharmacopeia (2002) Sections 2.6.1, 5.1, (4th Edn), European Directorate for the Quality of Medicines (EDQM), Strasbourg.

169. FDA-CBER (1997) Points to consider in the manufacture and testing of monoclonal antibody products for human use.

170. FDA (2001) Guidance for industry: bioanalytical method validation.

171. AAPS (2003) Workshop on bioanalytical method validation for macromolecules in pharmacokinetic profiling. 